TRABALHO DE GRADUAÇÃO

\title{
MODELAGEM DOS PROCESSOS DE IMPRESSÃO E ESCANEAMENTO
}

Anderson A. das Neves

Carlos V. de F.Silva

Brasília, Dezembro de 2008

UNIVERSIDADE DE BRASIILIA

FACULDADE DE TECNOLOGIA 
UNIVERSIDADE DE BRASILIA

Faculdade de Tecnologia

TRABALHO DE GRADUAÇÃO

\title{
MODELAGEM DOS PROCESSOS DE IMPRESSÃO E ESCANEAMENTO
}

\author{
Anderson A. das Neves \\ Carlos V. de F.Silva \\ Relatório submetido ao Departamento de Engenharia \\ Elétrica como requisito parcial para obtenção \\ do grau de Engenheiro Eletricista
}

Banca Examinadora

Ricardo L. de Queiroz, ENE/UnB

Orientador

Adolfo Bauchspiess, ENE/UnB

Examinador interno

Juliana Fernandes Camapum, ENE/UnB

Examinador interno 


\section{Dedicatórias}

Eu dedico este trabalho a todos que me deram suporte ao longo dos cinco anos de curso, pais, amigos, colegas, professores. Aos meios pais deixo um pensamento especial, pois foram estes que ofereceram a base de tudo que conquistei.

Carlos V. de F.Silva
Eu dedico este trabalho à minha mãe, por todo o apoio, por todo suporte e por toda confiança que tenho recebido dela para o estabelecimento e para o cumprimento de meus objetivos pessoais.. 


\section{Agradecimentos}

Eu agradeço ao professor Queiroz e a todos os integrantes do grupo Image UnB, em especial ao Zaghetto, ao Mintsu e ao Tiago, por haverem provido todo o apoio intelectual necessário ao desenvolvimento deste trabalho. Agradeço à minha família, pelo clima harmonioso de meu lar. Agradeço à minha amada Glaucia, por todo amor e por todo companheirismo dispensados a mim. E agradeço também ao Mestre Interno, por ser meu refúgio em todas as minhas atividades.

Anderson A. das Neves

Deixo meu sincero agradecimento aos colegas de graduação que me ajudram, aos professores que demonstraram interesse e dedicação pela área, ao Grupo de Processamento Digital de Sinais (GPDS). Deixo um agradecimento especial ao grupo IMAGE e seus membros, uma vez que, direta ou indiretamente, ofereceram o apoio fundamental no final do curso e decisivo ao traçar minha carreira.

Carlos V. de F.Silva 
Este trabalho visa modelar o canal formado pela impressão de imagens seguidas de seu escaneamento, também chamado de canal print-scan. O modelo proposto compreende três distorções existentes: distorção geométrica, de tonalidade e ruído gaussiano aditivo. Para diminuir os efeitos distorcivos do canal, são desenvolvidas ferramentas de correção geométrica e de tonalidade. A capacidade de recuperação de cores, através de um método particular, que permite o mapeamento reversível de cores e testuras, é utilizado como parâmetro de avaliação do modelo.

\begin{abstract}
This project aims to model the channel formed by printing and scanning pictures also called the print-scan channel. The proposed model incorporates the modelling of three distortions: geometric, reproduction tone and additive Gaussian noise. In order to reduce the distortion effects of the channel, tools are developed to perform of geometric and tone correction. The ability to recover colors, using a method, is used as a parameter for evaluating the model.
\end{abstract}




\section{SUMÁRIO}

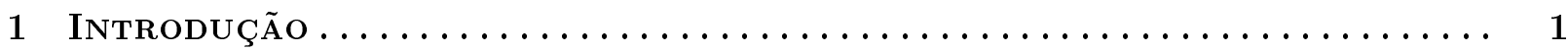

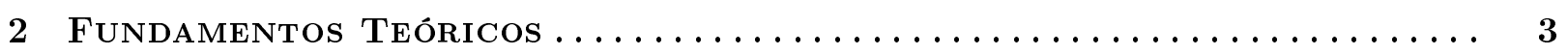

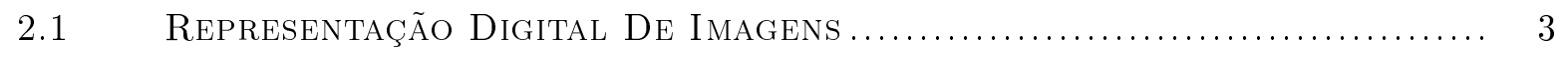

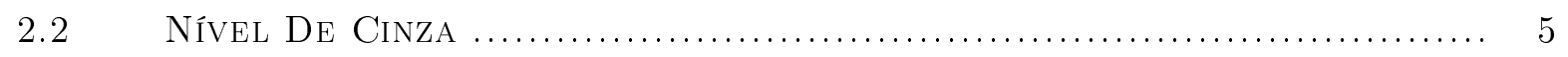

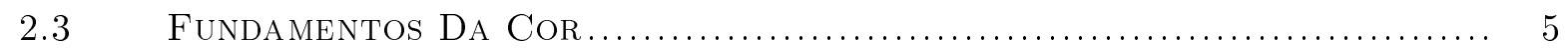

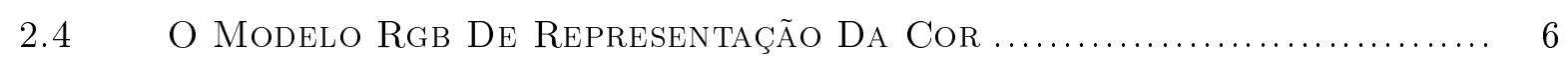

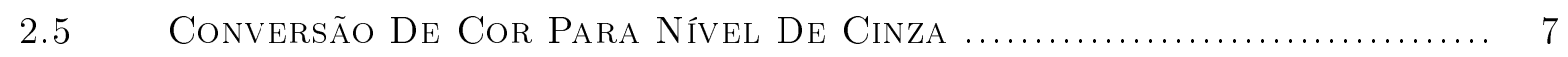

2.6 Transformação Reversível De Cor Para Nível De Cinza: Inserção De Texturas Nas Sub-Bandas De Alta Frequência................... 8

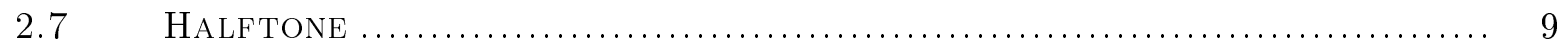

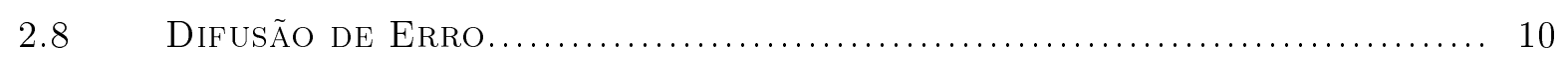

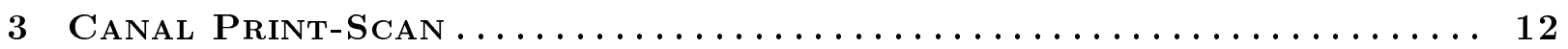

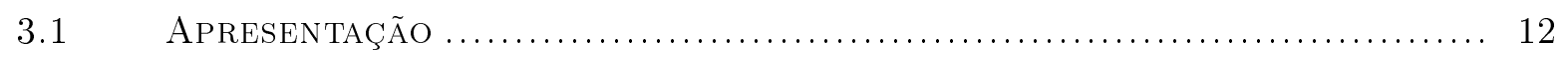

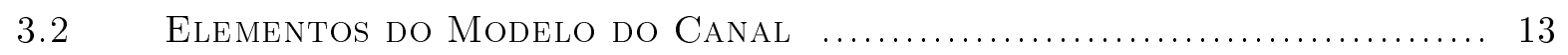

4 Metodologia .................................... 14

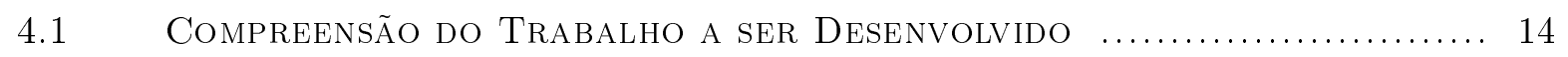

4.2 Determinação do Contorno do Projeto............................. 14

4.3 Mudança do Ambiente de Desenvolvimento ......................... 15

4.4 Construção da Função de Transferência e Função de Transferên-

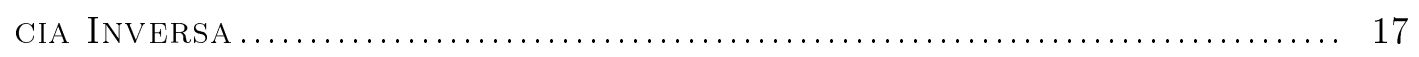

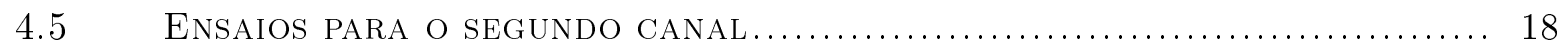

5 Corretor Geométrico e de Tonalidade $\ldots \ldots \ldots \ldots \ldots \ldots \ldots \ldots \ldots$

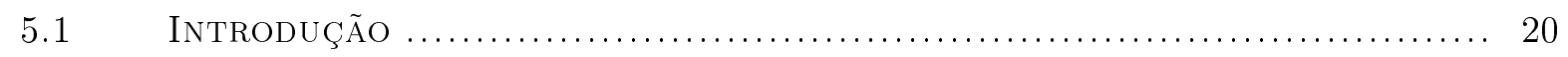

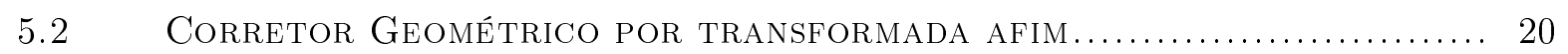

5.2.1 Importância do Corretor Geométrico na RecuperaÇão das Cores... 20

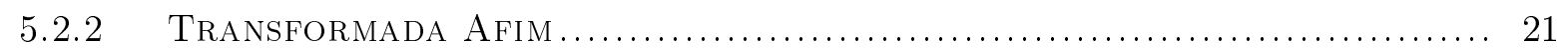

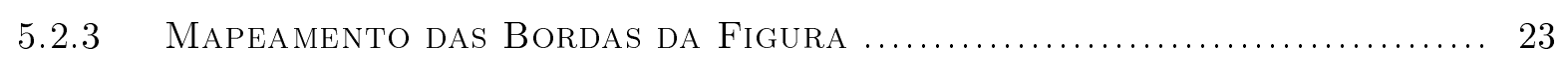

5.2 .4 Critério de SeleÇão de Pixels ............................................... 25

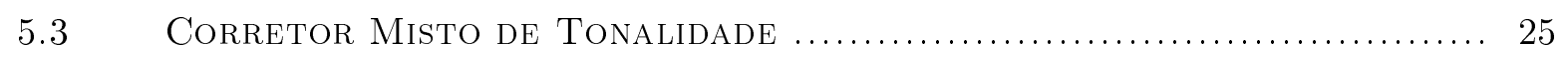

5.3.1 Função de Transferência saída-entrada pelo método do Centróide 26

5.3.2 Função de Transferência Segmentada Inversa ....................... 27 
5.3.3 Contexto como critério de não Ambiguidade da FunÇão de Trans-

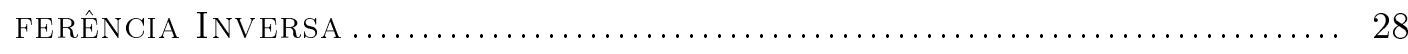

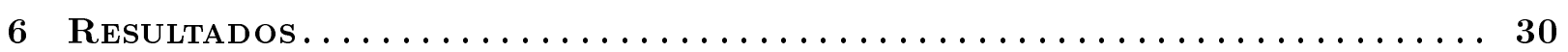

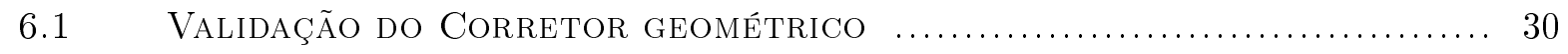

6.2 Imagem Corrigida Geometricamente e a Recuperação De Suas Co-

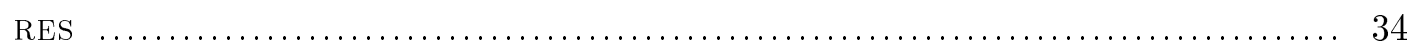

6.3 Ensaios Para Determinar a Função De Transferência ................. 39

6.4 AplicaÇão Da FunÇÃo De Transferência Inversa ...................... 48

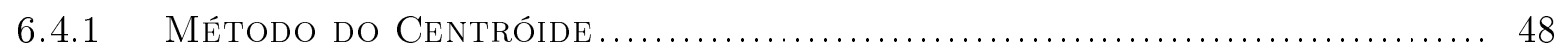

6.4.2 AplicaÇão da Função de Transferência Seguimentada Inversa $\ldots . . . . .53$

6.4.3 Método de anÁlise pelo contexto ................................. 57

6.5 ComparaÇão entre os Corretores de Tonalidade Propostos ......... 58

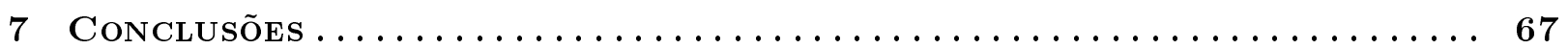

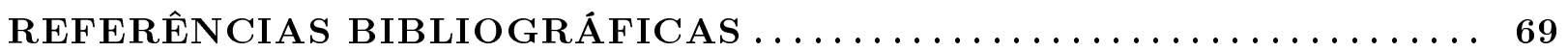

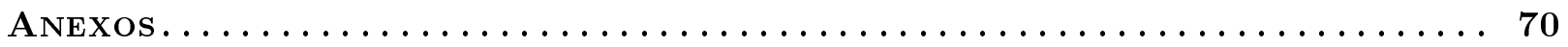

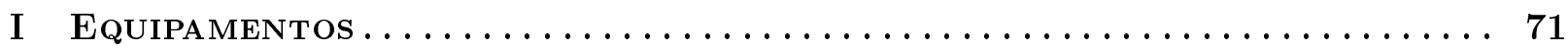

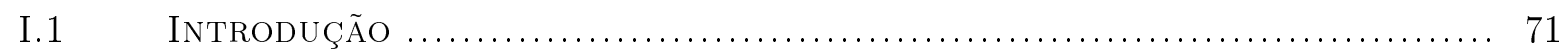

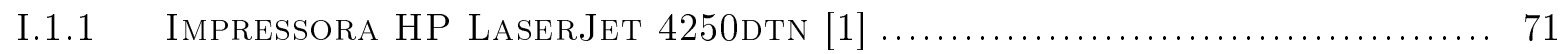

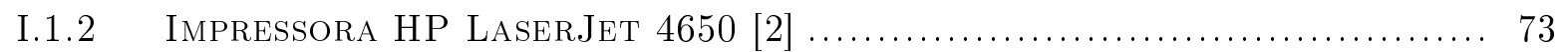

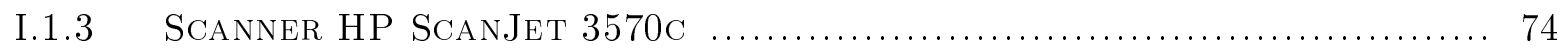




\section{LISTA DE FIGURAS}

2.1 Divisão da imagem em níveis discretos ([3] modificado): (a)imagem original, (b) resultado da amostragem

2.2 Influência do nível de quantização na qualidade da Fig. ([4], modificado):(a) imagem original, (b) imagem com 6 bits, (c) imagem com 4 bits, (d) imagem com 2 bits...... 4

2.3 Convenção do sistema de coordenadas usado para representar imagens digitais ([3],

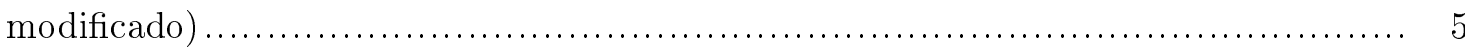

2.4 Esquemático do cubo RGB de cores. ([3] ,modificado) ............................ 7

2.5 Imagem RGB (a) e sua respectiva imagem convertida para nível de cinza (b) [5] ..... 7

2.6 Ilustração do método proposto, mostrando um exemplo das sub-bandas de uma transformada 4x4 $(\mathrm{M}=16)$, indicando a banda passa-baixa ou DC. Neste exemplo 3 cópias de cada canal de crominância foram alternadamente embutidos nas sub-

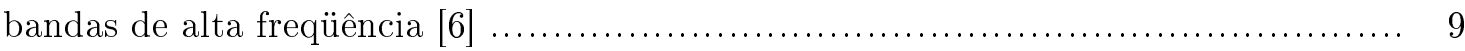

2.7 Método de halftone para uma imagem em escala de cinza ........................... 9

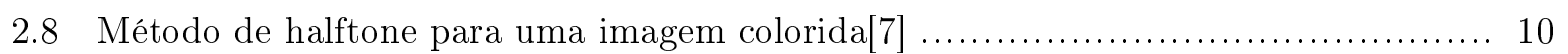

2.9 Difusão de erro para escala de cinza: (a) imagem original, (b) difusão de erro.......... 11

3.1 Ilustração dos equipamentos envolvidos envolvidos no canal print-scan ............... 12

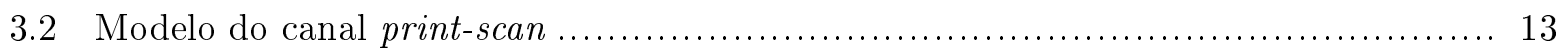

3.3 O canal print-scan, os corretores desenvolvidos e a sistemática do trabalho............. 13

4.1 Ilustração do canal print-scan para a texturização reversível de imagens coloridas .... 15

4.2 Metodologia adotada para realizar o modelamento do canal print-scan no mapeamento reversível de cores em texturas. .......................................... 16

4.3 Processo realizado para se obter as amostras de entrada e saída ...................... 17

5.1 Efeito da rotação no processo de recuperar de cores: (a) 0 grau, (b) 0,1 grau, (c)

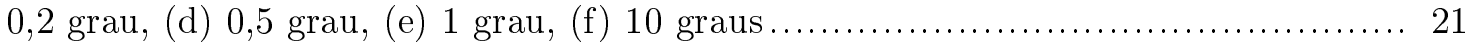

5.2 Localização das quinas de uma imagem utilizando o método por valor de limiar....... 24

5.3 Comparação entre a função de transferência e a função de transferência segmentada inversa (FTSI) do canal print-scan:(a) e (c) função de transfência, (b) e (d) FTSI. ... 28

5.4 Análise do Contexto para Imagem Barbara, onde o desvio da vizinhança é comparado para janelas de $3 \times 3$ e $5 \times 5$. O Desvio das janelas de $3 \times 3($ a) e $5 \times 5(b)$ é obtido da aplicação da FTSI composta dos segmentos $\mathrm{A}+\mathrm{b}$ e $\mathrm{A}+\mathrm{C}$. O desvio entre as duas composições de segmentos para FTSI são comparadas pela razão entre elas(c), e pela diferença $(\mathrm{d})$ 
6.1 Distribuições dos desvios entre a imagem simulada/corrigida e a imagem original:(a) Imagem Baboon, (b) Lena, (c) Barbara

6.2 Ilustração da área mapeada na imagem escaneada pela transformada afim. O valor do pixel na imagem corrigida pode ser determinado pela média, ponderada pela área do pixel contida na área mapeada, dos pixels que compõem essa área ................ 31

6.3 Imagens recuperadas após simulação e posterior correção geométrica .................. 33

6.4 Correção da imagem após a impressão e o escaneamento para os dois canais estudados. 34

6.5 Diferença absoluta entre a imagem corrigida e a original .......................... 35

6.6 Distribuição dos desvios entre a imagem corrigida e a imagem original, resultante do canal print-scan, para imagem Barbara.

6.7 Recuperação da cor da Imagem Baboon após transmiti-la via canal print-scan 1 (b) e 2 (c).

6.8 Recuperação da cor da Imagem Lena após transmiti-la via canal print-scan 1 (b) e

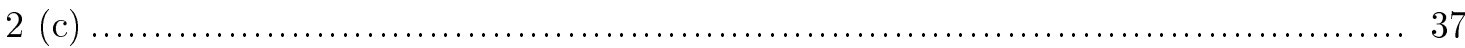

6.9 Recuperação da cor da Imagem Barbara após transmiti-la via canal print-scan 1 (b) e 2 (c)

6.10 Representação do número de eventos para cada par entrada, saída utilizando-se a impressora 1.

6.11 Função de Transferência obtida para canal print-scan, usando a impressora 1 e o scanner padrão.

6.12 Histograma dos desvio entre as amostras e o valor estimado pela função de transfe-

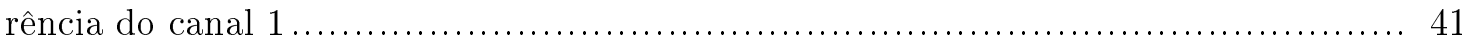

6.13 Regressão Gaussiana realizada na distribuição do ruído associado ao canal 1 ........ 43

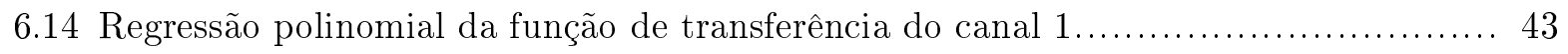

6.15 Comparação entre a função de transferência determinada pelo modelo (azul) e a função de transferência correspondente de três imagens tradicionais (vermelho)........ 44

6.16 Representação do número de eventos para cada par (entrada, saída) usando a Im-

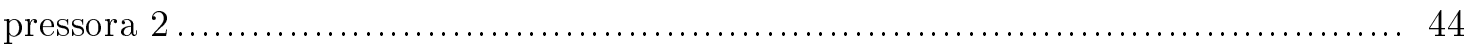

6.17 Função de transferência obtida utilizando-se a segunda impressora (curva azul) e sua respectiva regressão polinomial.

6.18 Comparação entre as funções de Transferência obtidas para as duas impressoras: Curva azul - Impressora 1; Curva vermelha - Impressora 2 ....................... 45

6.19 Distribuição do ruído associado ao canal 2 e sua respectiva regressão Gaussiana...... 46

6.20 Modelo obtido para o canal print-scan composto pela Impressora 1 .................. 47

6.21 Modelo obtido para o canal print-scan composto pela Impressora 2 ................. 48

6.22 Funções de transferência saída-entrada para os canais 1 (a) e 2 (b) ..................... 49

6.23 Regressão das funções de transferência saída-entrada dos canais 1 (a) e 2 (b).......... 49

6.24 Distribuição de desvios inerente à estimativa das funções de transferência saída-

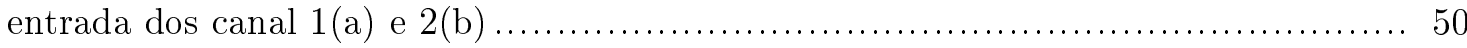

6.25 Comparação entre a imagem Baboon, impresso-escaneado e corrigido, antes (a) e

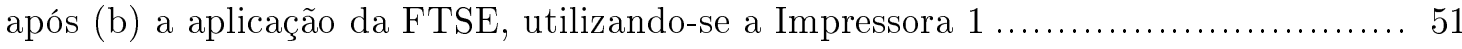

6.26 Comparação entre a imagem Baboon, impresso-escaneado e corrigido, antes (a) e após (b) a aplicação da FTSE, utilizando-se a Impressora 2 
6.27 Histogramas do desvio das imagens processadas em relação à original, antes (a) e depois (b) da aplicação da FTSE, para a Impressora 1 .

6.28 Histogramas do desvio das imagens processadas em relação à original, antes (a) e depois (b) da aplicação da FTSE, para a Impressora 2.

6.29 Ilustração dos 3 seguimentos da FTSI para impressora 1(a) e (c) e para impressora 2 (b) e (d). Os seguimentos são apresntados: azul - A, preto - B e vermelho - C ...... 53

6.30 Efeito resultante da aplicação da FTSI com diferentes arranjos de seguimentos da FTSI:(a) e (b) são resultados da imagem Baboon; (c) e (d) são da imagem Lena; (e) e (f) são da imagem Barbara; (a),(c) e (e) impressora 1; (b),(d) e (f) impressora 2. 56

6.31 Comparação da capacidade de recuperação de cor para imagem Baboon atrevés do canal print-scan composto pela impressora 1, sob as seguintes circunstancias: (a)corrigida geometricamente, (b)aplicada a FTSE, (c)aplicada a FTSI e (d)utilizado o método do contexto.

6.32 Comparação da capacidade de recuperação de cor para imagem Lena atrevés do canal print-scan composto pela impressora 1, sob as seguintes circunstancias: (a)corrigida geometricamente, (b)aplicada a FTSE, (c)aplicada a FTSI e (d)utilizado o método do contexto.

6.33 Comparação da capacidade de recuperação de cor para imagem Barbara atrevés do canal print-scan composto pela impressora 1, sob as seguintes circunstancias: (a)corrigida geometricamente, (b)aplicada a FTSE, (c)aplicada a FTSI e (d)utilizado o método do contexto.

6.34 Comparação da capacidade de recuperação de cor para imagem Baboon atrevés do canal print-scan composto pela impressora 2, sob as seguintes circunstancias: (a)corrigida geometricamente, (b)aplicada a FTSE, (c)aplicada a FTSI e (d)utilizado o método do contexto.

6.35 Comparação da capacidade de recuperação de cor para imagem Lena atrevés do canal print-scan composto pela impressora 2, sob as seguintes circunstancias: (a)corrigida geometricamente, (b)aplicada a FTSE, (c)aplicada a FTSI e (d)utilizado o método do contexto.

6.36 Comparação da capacidade de recuperação de cor para imagem Barbara atrevés do canal print-scan composto pela impressora 2, sob as seguintes circunstancias: (a)corrigida geometricamente, (b)aplicada a FTSE, (c)aplicada a FTSI e (d)utilizado o método do contexto.

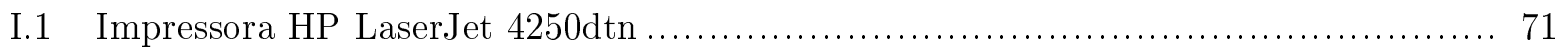

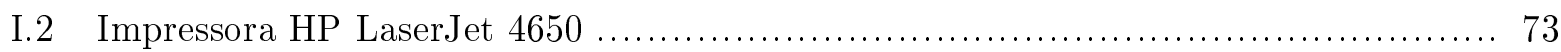

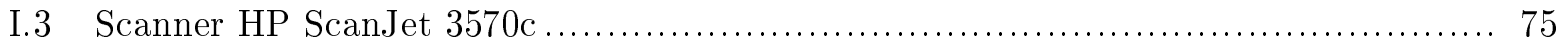




\section{LISTA DE TABELAS}

5.1 Dimensão de imagem resultante de cada resolução de escaneamento .................. 25

6.1 Porcentagem do erro do desvio concentrada em uma dada faixa (ou valor) ............. 31

6.2 Principais parâmetros das curvas de desvio resultantes do canal print-scan ............ 35

6.3 Principais características associadas ao histograma de desvios inerentes à função de

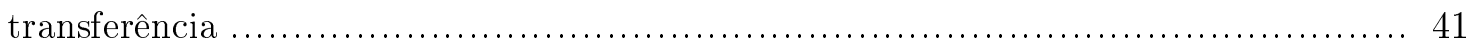

6.4 Principais características associadas ao histograma de desvios inerentes à função de transferência associada à segunda impressora ....................................... 46

6.5 Principais parâmetros das curvas das Figs. 6.24(a) e (b).......................... 50

6.6 Porção do montante total de pixels da figura corrigida geometricamente, presentes em cada intervalo. ................................................................. 54

6.7 Ganho de redução de erro em relação à imagem sem aplicar FTSI para diversos arranjos de seguimentos da FTSI, aplicadas em imagens obtidas através da impressora

1. Valores em Pixels.

6.8 Ganho de redução de erro em relação à imagem sem aplicar FTSI para diversos arranjos de seguimentos da FTSI, aplicadas em imagens obtidas através da impressora

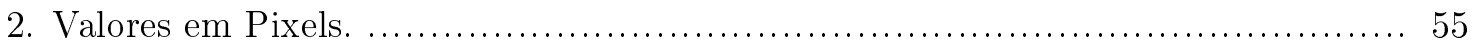

6.9 Erro médio dos diferentes arranjos de seguimento da FTSI, para impressora $1 \ldots \ldots \ldots 57$

6.10 Erro médio dos diferentes arranjos de seguimento da FTSI, para impressora $2 \ldots \ldots \ldots 58$

6.11 Comparação dos parâmetros das curvas de desvios antes e depois da aplicação da função de transferência saída-entrada. .......................................... 59

6.12 Comparação dos parâmetros das curvas de desvios antes e depois da aplicação da função de transferência saída-entrada. .............................................. 59

I.1 Descrição da Impressora HP LaserJet 4250dtn ....................................... 72

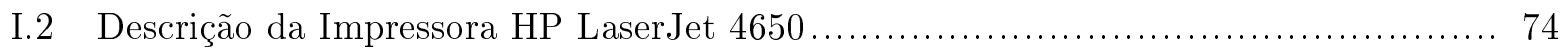




\section{LISTA DE SÍMBOLOS}

\section{Siglas}

Print-Scan Canal que compreende a impressão de imagens seguidas de seu escaneamento

$F T$

Função de tranferência do canal

FTSE

Funsão de Transferência Saida $\rightarrow$ Entrada

FTSI

Funsão de Transferência Seguimentada Inversa

\section{Funções}

$\begin{array}{ll}r_{1}(x) & \text { Distribuição gaussiana de ruído do canal print-scan composto pela impres- } \\ & \text { sora } 1 \\ r_{2}(x) & \text { Distribuição gaussiana de ruído do canal print-scan composto pela impres- } \\ & \text { sora } 2 \\ r n_{1}(x) & \text { Distribuição gaussiana de ruído normalizada do canal print-scan composto } \\ & \text { pela impressora } 1 \\ r n_{2}(x) & \text { Distribuição gaussiana de ruído normalizada do canal print-scan composto } \\ F T_{1}(x) & \text { pela impressora } 2 \\ F T_{2}(x) & \text { Função de tranferência do canal composto pela impressora } 1 \\ F T S E_{1}(x) & \text { Função de tranferência do canal composto pela impressora } 2 \\ & \text { Função de Transferência Saida } \rightarrow \text { Entrada, FTSE, do canal composto pela } \\ F T S E_{1}(x) & \text { impressora } 1 \\ & \text { Função de Transferência Saida } \rightarrow \text { Entrada, FTSE, do canal composto pela } \\ F T S I_{2}(x) & \text { impressora } 2 \\ F T S I_{2}(x) & \text { Função de Transferência Seguimentada Inversa, FTSI, do canal composto } \\ & \text { pela impressora } 1\end{array}$




\section{Capítulo 1}

\section{Introdução}

Documentos coloridos, cada vez mais, fazem parte da rotina de escritórios, onde são produzidos, armazenados e disponibilizados em formatos eletrônicos. Freqüentemente surge a necessidade de se imprimir esses documentos visando sua circulação, e como boa parte dos escritórios estão equipados com impressoras a laser preto e branco, esta impressão é comumente monocromática. Muitas vezes o documento eletrônico original é perdido ou não se faz disponível. Desta forma, pode-se também desejar retornar essa imagem impressa ou transmitida via fax ao formato eletrônico, através do escaneamento.

Na impressão de documentos coloridos em dispositivos monocromáticos, é necessário a conversão de cores em nível de cinza. Na conversão padrão de cor para nível de cinza é comum mais de uma cor realizar o mapeamento para o mesmo nível de cinza. Assim, caso se deseje recuperar futuramente a informação de cor a partir da imagem monocromática, é necessário utilizar um método que mapeie cores diferentes para diferentes representações em nível de cinza. Na referência [8], cujo um dos autores é orientador do presente projeto, foi desenvolvido um método reversível com esta característica. Em [6] elaborou-se um método semelhante ao acima [8], porém com resultados mais robustos. Este método, cujo funcionamento será explicado neste trabalho, insere as informações de cores na imagem monocromática através de texturas.

Ao se testar esse método para imagens de origem eletrônica, convertendo-se a imagem colorida em monocromática texturizada e em seguida aplicando o processo reverso a esta, obteve-se bons resultados. Porém, ao se imprimir e escanear a imagem texturizada, alguns problemas aparecem:

- A configuração geométrica da imagem é alterada

- O valor dos pixels é alterado

- Ruído é inserido na imagem

Devido a esses processos, a recuperação de cor da imagem resultante não mais é fiel à imagem original, gerando resultados desastrosos. Na seção 5.2.1 é ilustrado um exemplo. 
O canal print-scan é definido como o processo de imprimir um documento e escaneá-lo em sequência. Desta forma, o documento, assumidamente uma imagem, é recuperado no receptor com uma certa distorção. Ou seja, do computador transmissor (que comandou a impressão) ao computador receptor (conectado ao scanner) houve uma transmissão ruidosa da informação da imagem pelo canal print-scan.

Desejamos, aqui, tentar modelar tal canal, de modo a obter um conjunto de métodos para o processamento digital a ser aplicado na imagem impressa-escaneada, de forma a corrigir, com um mínimo de erro, as distorções geradas pelo canal print-scan. 


\section{Capítulo 2}

\section{Fundamentos Teóricos}

\subsection{Representação Digital De Imagens}

Na natureza, todos os objetos de nossa visão apresentam uma faixa contínua de variação em seus valores (se formos atribuir valores com grande precisão) de cor; e, obviamente, contínua é também sua característica física. Dessa forma, ao se pensar em representar digitalmente as imagens, dois processos devem ser realizados: a amostragem e a quantização. Os conceitos desenvolvidos nesta seção se basearam no exposto em [3].

A amostragem discretiza as dimensões físicas da imagem, determinando a resolução com que serão obtidas as informações das cores. Em outras palavras, a amostragem indica qual o espaçamento entre duas tomadas de valores consecutivas da imagem. Observe a discretização realizada nas coordenadas x e y da Fig. 2.1(a), onde será capturado o valor encontrado no meio do quadrado para representar toda sua área, e seu correspondente resultado. A imagem amostrada ficou distorcida devido à baixa resolução de amostragem utilizada, $12 \times 14$ pixels.

Já a quantização atribui o valor correspondente a cada amostra segundo um critério que escolhe um valor entre uma faixa de valores discretizados, sendo escolhido aquele que mais se aproxima do valor medido. Geralmente, por praticidade, esses valores discretos são números inteiros. Quanto mais próximos estiverem esses valores, diz-se que maior é o nível de quantização e, por conseguinte, mais preciso é o resultado. A Fig. 2.2 ilustra a influência do nível de quantização na qualidade da Fig. 2.1.

Após se realizar a amostragem e a quantização, o resultado é a formação de uma matriz de números reais, onde cada elemento da matriz corresponderá ao valor de um pixel da imagem. Adotando-se a notação de funções para representar a imagem, $\mathrm{f}(\mathrm{x}, \mathrm{y})$, e considerando que a imagem foi amostrada de forma tal a ter $M$ linhas e $N$ colunas, os valores das coordenadas (x,y) assumirão

(a) (b)

Figura 2.1: Divisão da imagem em níveis discretos ([3] modificado): (a)imagem original, (b) resultado da amostragem 


\section{(a) $\quad(\mathrm{b}) \mathrm{c}) \quad(\mathrm{d})$}

Figura 2.2: Influência do nível de quantização na qualidade da Fig. ([4], modificado):(a) imagem original, (b) imagem com 6 bits, (c) imagem com 4 bits, (d) imagem com 2 bits

Figura 2.3: Convenção do sistema de coordenadas usado para representar imagens digitais ([3], modificado)

agora valores discretos. A convenção do sistema de coordenadas para a representação de imagens digitais é diferente do sistema cartesiano comum habitual. Neste os valores das coordenadas crescem da esquerda para a direita e de baixo para cima, localizando a origem (considerando o primeiro quadrante) no canto inferior esquerdo. Naquele os valores crescem da esquerda para a direita e de cima para baixo, localizando a origem no canto superior direito. A Fig. 2.3 ilustra o sistema de coordenadas usado para representar imagens digitais.

\subsection{Nível De Cinza}

O nível de cinza é uma forma de representar digitalmente imagens monocromáticas. Sua acurácia depende de quantos bits são utilizados para codificar os tons de cinza entre o branco e o preto. Usando-se $B$ bits, será possível o uso de $2^{B}$ níveis para expressar o valor do pixel.

O número de bits mais comumente usado nessa representação é 8, o que permite 256 intensidades diferentes. Convencionou-se 0 para indicar o preto e 255 para branco. Em aplicações específicas, em que é requerida uma maior precisão para se evitar erros de arredondamento, é comum o uso de 16 bits [3]. As imagens médicas são um exemplo.

\subsection{Fundamentos Da Cor}

O processo de percepção e interpretação das cores pelo cérebro não é ainda completamente conhecido, todavia resultados teóricos e experimentais permitem a formulação de uma base teórica que expresse a natureza física da cor. O exposto nesta seção baseia-se na teoria apresentada em [3].

A sensação de percepção da cor pelos humanos e por alguns animais é determinada pela luz refletida dos objetos visualizados. A luz visível é composta por uma faixa de freqüência relativamente estreita no espectro eletromagnético. Um corpo que reflete luz balanceada em todos os comprimentos de luz do espectro visível aparenta ser branco ao observador. Já um corpo que favorece a refletância da luz no comprimento $700 \mathrm{~nm}$, por exemplo, aparenta vermelho.

São usados três atributos para se caracterizar a qualidade da luz: A radiância, a luminância e o brilho. A radiância é medida da quantidade de energia emitida pela fonte luminosa, medida geralmente em watts $(\mathrm{W})$. A luminância se refere à quantidade de energia percebida pelo observador da fonte e é medida em lumens (lm). Já o brilho é uma característica impossível de ser medida, 
Figura 2.4: Esquemático do cubo RGB de cores. ([3] ,modificado)

sendo uma descrição subjetiva. Seu conceito envolve a percepção acromática de intensidade e é um dos principais fatores na caracterização da sensação de cor.

Devido às características de absorção da luz pelo olho humano, as cores são vistas como uma combinação de três cores primárias: vermelho, verde e azul. Para efeitos de padronização, estabeleceu-se o comprimento de onda específico das cores primárias: $435.8 \mathrm{~nm}$ para o azul, 546,1 para o verde e 700 para o vermelho. Porém deve-se tomar cuidado para não se cometer uma confusão neste ponto. Estabelecer estas três cores específicas como sendo primárias não significa que todas as outras cores do espectro podem ser geradas a partir delas. Para tal é necessário também alterar o comprimento de onda. Em outras palavras, qualquer cor do espectro pode ser obtida a partir da combinação dos vários tons de azul (escolhendo um por vez), com os vários tons de verde e com os vários tons de vermelho; mas nem todas podem ser geradas a partir da combinação dos três tons específicos definidos e padronizadas como primárias.

As características usadas para se distinguir uma cor de outra são o brilho, a matiz e a saturação. O brilho, já referido anteriormente, diz respeito à noção acromática de intensidade. A matiz está associada ao comprimento de onda predominante em uma mistura de ondas de luz. Dessa forma, quando dizemos que dado objeto é verde ou amarelo, estamos especificando sua matiz. Por sua vez, a saturação se relaciona à pureza relativa ou à quantidade de luz branca misturada com a matiz. As cores de espectro puro são completamente saturadas e o nível de saturação é inversamente proporcional à quantidade de branco misturada.

\subsection{O Modelo Rgb De Representação Da Cor}

Esta seção foi escrita com base em [3]. O modelo RGB (Red-Green-Blue) representa as cores a partir de suas componentes relativas a cada uma das cores primárias, vermelho, verde e azul. Logo, são utilizados três valores na determinação da cor de cada pixel, correspondentes aos seus componentes primários. Dessa forma, a imagem será representada digitalmente por uma matriz MxNx3, que é uma concatenação de três matrizes $\mathrm{MxN}$, sendo, cada uma, a quantização de quanto de uma determinada cor primária cada pixel da imagem possui.

O número de cores possíveis a serem representadas é determinado pelo bit depth, que nada mais é do que o número de bits utilizados para se designar um valor de cor. Um tipo de precisão muito usado atualmente é o famoso full-color, que usa 8 bits para codificar cada componente primário da cor. Dessa forma tem-se $3 \times 8=24$ bits para se representar a cor de cada pixel da imagem, resultando em $2^{24}=16.777 .216$ combinações possíveis.

Pode-se fazer uma analogia do modelo RGB com o sistema de coordenadas cartesianas. O cubo que representaria o subespaço de interesse está na Fig. 2.4. Cada um dos eixos cartesianos representa uma cor primária. A origem representa o preto, a coordenada $(255,255,255)$ o branco, e a diagonal que vai da origem ao seu canto oposto (que possui valores RGB iguais) representa a escala em Nível de Cinza. 
(a) (b)

Figura 2.5: Imagem RGB (a) e sua respectiva imagem convertida para nível de cinza (b) [5]

\subsection{Conversão De Cor Para Nível De Cinza}

Para converter uma imagem colorida para a escala de nível de cinza é necessário, primeiramente, ter isoladamente os valores das três componentes (considerando o modelo RGB) primitivas da imagem. Uma solução seria, então, combinar $30 \%$ do valor do componente vermelho, $59 \%$ do componente verde e $11 \%$ do componente azul. O valor em nível de cinza estará determinado após somar esses três valores [5].

Esse método foi desenvolvido levando-se em conta a sensibilidade do olho humano para as cores primárias [5]. Vale lembrar, como já mencionado no capítulo da introdução, esse método não é reversível em sua forma pura e necessita de ferramentas adicionais caso se pense em recuperar as cores a partir da imagem monocromática.

\subsection{Transformação Reversível De Cor Para Nível De Cinza: Inser- ção De Texturas Nas Sub-Bandas De Alta Frequência}

O método mais simples de converter uma imagem colorida para escala de cinza é reter e utilizar os componentes de luminância da imagem colorida. Porém, um requisito essencial ao processo a ser desenvolvido e utilizado para converter imagens coloridas em nível de cinza, é que ele seja reversível. Logo, o método citado não é adequado aos objetivos deste projeto, pois cores diferentes possuindo luminância similares resultariam em um mesmo mapeamento na escala de cinza. Em [8] e [6] foram desenvolvidos dois métodos de mapeamento reversível, optamos por utilizar o mais robusto.

O citado método mapeia as cores em texturas de alta freqüência. Analisando as texturas o usuário pode recuperar a informação de cor para cada região. A inserção dessas texturas é realizada seguindo o seguinte procedimento [6]:

- A imagem colorida, representada no espaço RGB, é transformada para os planos $\mathrm{Y}, \mathrm{Cb}$, Cr usando transformada de cor linear RGB-YCbCr, gerando, assim, um espaço luminânciacrominância. No espaço de representação YCbCr, o plano Y representa a luminância e os planos $\mathrm{Cb}$ e $\mathrm{Cr}$ as informações de crominância.

- Aplica-se uma transformada de sub-bandas genérica com $M$ bandas ao canal de luminância. Verificou-se que a Transformada de Cosseno Discreta (TCD) é mais robusta em seus resultados. No método desenvolvido em [8] utilizou-se a Transformada Wavelet Discreta, que usa apenas 4 sub-bandas. Através de uma transformada com $M$ sub-bandas, com $M$ assumindo usualmente valores bem acima de $4(16,64$, por exemplo), obtém-se redundância na informação de cor, resultando em um método mais robusto. 
Figura 2.6: Ilustração do método proposto, mostrando um exemplo das sub-bandas de uma transformada 4x4 $(\mathrm{M}=16)$, indicando a banda passa-baixa ou DC. Neste exemplo 3 cópias de cada canal de crominância foram alternadamente embutidos nas sub-bandas de alta freqüência [6]

- Dividindo-se os canais de crominância em $N_{S}$ sub-bandas, realiza-se uma combinação linear dessas sub-bandas para inserir os planos $\mathrm{Cb}$ e Cr, como ilustrado na Fig. 2.6.

- Substitui as últimas $N$ sub-bandas de alta freqüência resultantes da TCD pelas informações de crominância resultantes do passo anterior.

No processo de recuperação das cores a partir da imagem texturizada devemos apenas reverter os procedimentos adotados no mapeamento de cor para nível de cinza, seguindo os seguintes passos.

- Aplica-se a TCD para imagem em escala de cinza.

- Recupera os planos de crominância a partir das $N$ últimas sub-bandas de alta freqüência aplicando o processo reverso da combinação linear utilizada na inserção das texturas.

- Leva para 0 as sub-bandas que foram usadas para embutir crominância.

- Aplica-se a TCD inversa nas sub-bandas resultantes, produzindo o plano de luminância.

- Converte-se os planos de luminância e crominância de volta à representação RGB.

\subsection{Halftone}

O halftone é uma técnica de reprodução de imagens digitais em papel ou outros meios semelhantes. Uma imagem gerada em computador utiliza o formato RGB, onde cada cor é criada a partir da gradação da intensidade luminosa em cada elemento de cor RGB (Vermelho, Verde e Azul), contudo, o meio impresso não dispõe da mesma capacidade de gradação de tonalidade. A tinta ou tonner de impressão não podem ser diluídos, portanto, tendo sempre o mesmo tom.

Figura 2.7: Método de halftone para uma imagem em escala de cinza

Para contornar este problema, é utilizada a técnica de halftone. O método consiste na construção de arranjos com uma quantidade grande de pontos, variando desde o tamanho e forma do ponto, como também o espaçamento entre eles. A Fig. 2.7 ilustra o halftone com a variação de espaçamento e dimensões dos pontos impressos.

Como o olho humano não consegue distinguir elementos menores que um certo limite, arranjos de pontos em papel branco produzem a ilusão de um tom acinzentado, no caso de halftone apenas com cor preta. O halftone também é utilizado para construção de imagens impressas coloridas, como pode ser visto na Fig. 2.8. No caso do halftone em cores, são utilizados 4 tipos de tonalidade: 
- Ciano

- Majenta

- Amarelo

- Preto

O preto pode ser obtido a partir das outras cores, no entanto, como a quantidade de produto necessária para tanto é elevada, a cor preta é usada para baratear a impressão. Uma aprofundamento maior nos diferentes métodos de halftone pode ser visto na Ref. [7].

Figura 2.8: Método de halftone para uma imagem colorida[7]

\subsection{Difusão de Erro}

A difusão de erro é um tipo de halftone onde o erro quantizado é distribuído na vizinhança do pixel que ainda não foi processado. O método por difusão de erro tem a tendência a acentuar as bordas da imagem, o que é interessante quando se trata de impressão de texto, tornando-o mais legível.

O método pode ser utilizado com apenas uma dimensão, para tanto, a imagem deve ser organizada em vetores. Cada pixel é comparado com o valor do meio da escala de cinza, se for menor, um pixel preto é gerado, caso contrário, um pixel branco. Como o pixel gerado não é completamente preto, nem tão pouco branco, o erro gerado é propagado (difundido) ao próximo pixel, e assim segue o processo.

O funcionamento da Difusão de Erro com duas dimensões é similar ao de uma dimensão, sendo apenas necessário um a adição de um quarto do erro ao pixel da linha de baixo e ao pixel posterior ao pixel da linha de baixo. A difusão de erro em duas dimensões reduz o surgimento de linhas verticais na imagem gerada.

(a) (b)

Figura 2.9: Difusão de erro para escala de cinza: (a) imagem original, (b) difusão de erro 


\section{Capítulo 3}

\section{Canal Print-Scan}

\subsection{Apresentação}

O processo de impressão e escaneamento não são imunes ao aparecimento de distorções e ruídos. Além dos equipamentos utilizados (impressora, fax e scanner), o manuseio, a origem e o amazenamento do papel são elementos importantes no momento do modelamento do Canal de impressão e escaneamento, ou simplesmente, print-scan. A Fig. 3.1 ilustra a conversão da imagem para o formato monocromático, do canal print-scan e dos equipamentos participantes.

Figura 3.1: Ilustração dos equipamentos envolvidos envolvidos no canal print-scan 


\subsection{Elementos do Modelo do Canal}

O canal print-scan está sucetível a distoções de características distintas, ficando praticamente impossível construir um modelo teórico. Como vários equipamentos são utilziados, cada um afetado por um conjunto de fatores diferente, será construído um modelo empírico. As distorções mais significantes são:

- Distorção Geométrica.

- Aparecimento de ruído aleatório aditivo.

- Distorção de Tonalidade.

A distorção geométrica, que corresponde à alteração das dimensões e da posição da figura, pode ser corrigida pelo Corretor Geométrico a ser desenvolvido (seção 5.2). A distorção de Tonalidade, decorrente do fato da lâmpada do scanner ter limitações de percepção de tonalidade e a imprecisão do halftone de representar os tons de cinza, pode ser modelada a partir de uma função de transferência, e sua correção feita pelo Corretor de Tonalidade (seção 5.3). O ruído adicionado, devido à característica estocástica, não poderá ser corrigido, mas será mensurado em análises posteriores.

A Fig. 3.3 demonstra como será feita a interação entre o canal print-scan, o algorítimo de recuperação de cor e os Corretores Geométricos e de Tonalidade.

Figura 3.3: O canal print-scan, os corretores desenvolvidos e a sistemática do trabalho. 


\section{Capítulo 4}

\section{Metodologia}

\subsection{Compreensão do Trabalho a ser Desenvolvido}

Através do exposto neste trabalho, são verificados dois problemas promovidos pelo processo de impressão e escaneamento: primeiro, a distorção geométrica sobre a imagem original; segundo, a distorção dos valores dos pixels da imagem original. Para contornar estes problemas, será construído um código corretor da distorção geométrica (visto em detalhe na seção 5.2), um código corretor de tonalidade (visto em detalhe na seção 5.3) e o modelo do canal distorcivo compreendido pelos processos de impressão e escaneamento. O diagrama da Fig. 4.1 ilustra a metodologia adotada, aplicada ao processo de conversão reversível de imagens coloridas em texturas monocromáticas.

Para que seja efetuada a restauração das cores da imagem, é preciso aplicar o método de inserção das informações de cores através do mapeamento de texturas antes de imprimir e escanear a imagem. Este método foi apresentado na seção 2.6 e sua implementação é obtida através do código em MatLab fornecido pelo autor da referencia [8], orientador deste projeto.

\subsection{Determinação do Contorno do Projeto}

A Fig. 4.2 apresenta a metodologia adotada. Inicialmente, a imagem texturizada é impressa e escaneada.

Para que fosse possível construir um escopo inicial para o projeto, não incorrendo em grande complexidade na fase inicial, utilizamos apenas uma impressora e um scanner. Mais à frente, na seção 6, é utilizada uma segunda impressora. A impressora selecionada foi o modelo HP Laserjet 4250dtn (impressora 1 vide anexo I.1.1, a laser monocromática) e como scanner, o modelo HP ScanJet 3570c (scânner 1 vide anexo I.1.3), ambos localizados no laboratório do Grupo de Processamento Digital de Sinais (GPDS) da UnB.

Figura 4.1: Ilustração do canal print-scan para a texturização reversível de imagens coloridas 
Figura 4.2: Metodologia adotada para realizar o modelamento do canal print-scan no mapeamento reversível de cores em texturas.

Após este processo, avança-se para a etapa de correção das distorções geométricas. Para corrigir os efeitos geométricos aplicados na imagem, optamos pela transformada afim, explicada na seção 5.2. A utilização dessa transformada visa à correção requerida, construída em código de programação computacional.

O MatLab é uma linguagem de alto nível que possui diversas funções úteis a diversas áreas da ciência, entre as quais o processamento de sinais, implementadas em bibliotecas chamadas toolbox, construídas pela mesma empresa que produziu o MatLab, a MathWorks. Essa linguagem realiza seu processamento através de cálculos matriciais. Apesar da transformada afim realizar cálculos matriciais, há várias operações, em sua implementação, que não necessitam desse tipo de cálculo. Dessa forma, vários cálculos que poderiam ser realizados de forma linear são feitos através de operações matriciais ao construir o código em MatLab. Isso faz com que o tempo de processamento seja bem superior ao de outras linguagens, como o $\mathrm{C}++$. Há então uma relação de ganho e benefício a ser analisada antes da escolha da linguagem a ser utilizada. Por ser uma linguagem que proporciona uma maior facilidade na construção e depuração do código, o MatLab foi a nossa primeira escolha.

\subsection{Mudança do Ambiente de Desenvolvimento}

Contudo, as versões preliminares do código em Matlab, construídas e testadas, apresentaram um consumo elevado de tempo de processamento. Isso se deve ao tamanho da imagem que serve de entrada para o código, com tamanhos usuais na faixa de $3 \mathrm{MB}$ à $170 \mathrm{MB}$. Tais dimensões adquirem grandes proporções devido às altas resoluções utilizada no escaneamento, que foram de 1000 e 1200 dpi.

Resolveu-se então migrar o código MatLab para a linguagem $\mathrm{C}++$, linguagem mais veloz em termos de processamento e também mais complexa. Um tempo considerável foi tomado na depuração e no ajuste do código, porém, conseguiu-se obter os resultados desejados juntamente com um curto tempo de processamento. Os resultados obtidos nessa parte encontram-se no capítulo 6 .

A partir da implementação da transformada afim, tornou-se possível partir para duas outras etapas: testar a recuperação das cores da imagem corrigida e proceder para a determinação da função de transferência do canal print-scan e sua respectiva distribuição de ruído.

Os testes de recuperação das cores da imagem corrigida foram realizados através do código par (inserção/recuperação da textura) daquele utilizado para inserir as texturas na imagem,conforme pode ser visto na Fig. 4.1. Embora já possa ser constatada a capacidade de recuperação das cores, ainda existe possibilidade de melhora com a utilização da função de transferência inversa. 
Figura 4.3: Processo realizado para se obter as amostras de entrada e saída

\subsection{Construção da Função de Transferência e Função de Transfe- rência Inversa}

Para se determinar a função de transferência do processo é necessário, primeiramente, coletar várias amostras com valores de entrada e saída do canal print-scan. Com esse objetivo, geramos imagens em gradiente, tanto horizontal como vertical, contendo, cada uma, os 256 valores da escala de cinza. Para obtermos resultados mais abrangentes, geraram-se imagens em diversos tamanhos: $32 \times 32,32 \times 64,64 \times 64,64 \times 128,128 \times 128,128 \times 256$ e $256 \times 256$.

As imagens geradas foram, em seguida, submetidas ao canal de impressão e escaneamento e ao código de correção da distorção geométrica. Nos ensaios, tem-se, então, como entrada a imagem gerada e como saída a imagem processada resultante do código da transformada afim. Como o canal print-scan apresenta um comportamento não homogêneo (isto é, imprimindo-se e escaneando $N$ vezes uma mesma imagem, os pixels com valor ' $\mathrm{x}$ ' na imagem original muito dificilmente irão todos ser mapeados em um mesmo valor 'y' na imagem corrigida), há a necessidade de se obter um número muito grande de amostras para se fazer um modelamento estatístico do canal. Para atender a tal necessidade realizamos o processo ilustrado na Fig. 4.363 vezes. Coletando os valores de saída dessas imagens foi possível obter 1280 amostras para cada um dos 256 níveis de cinza.

Para determinar a função de transferência a partir das amostras, deve-se calcular o centróide para cada valor de entrada. Usa-se a seguinte fórmula no cálculo do centróide:

$$
c(x)=\frac{\sum_{x=1}^{n} x \cdot f(x)}{\sum_{x=1}^{n} f(x)}
$$

onde $n$ é o número de amostras para cada valor de entrada $x$, que no nosso caso é 1280 .

A determinação da função de transferência terá, basicamente, três utilidades:

- Informação qualitativa e quantitativa para o modelamento do canal print-scan.

- Aplicá-la sobre as imagens originais e verificar qual a distribuição do ruído inerente ao canal print-scan

- Aplicar a função de transferência inversa sobre a imagem impressa e escaneada corrigida.

A aplicação do centróide fornece um mapeamento de entrada e saída. Caso se deseje gerar dados mais objetivos para se quantificar melhor o processo, é necessário realizar uma regressão e obter uma função que passe pelos pontos mapeados. Optamos pela regressão polinomial de quarto grau e utilizamos a ferramenta do MatLab denominada cftool para este objetivo.

Devido à presença de ruído no canal de impressão e escaneamento, a função de transferência apresentará um nível de erro. Este pode ser mensurado através do modelamento do referido ruído. 
A distribuição desse ruído pode ser feita aplicando-se a função de transferência sobre a imagem original e comparando-a com a imagem resultante da transformada afim (impressa-escaneadacorrigida).

Por último há a aplicação com potenciais mais promissores e desejados do projeto: a aplicação da função de transferência inversa sobre a imagem corrigida, visando-se obter na saída uma imagem mais próxima o possível da imagem texturizada original. E quanto maior a proximidade melhor será a precisão das cores recuperadas. Para que uma função seja inversível, um dos requisitos é que ela seja bijetora, ou seja, cada valor de saída corresponde a somente um valor de entrada. Neste ponto surgiu um problema a ser resolvido: em certas faixas da função de transferência mais de um valor de entrada correspondem ao mesmo valor de saída. Escolhemos três métodos diferentes para solucionar esse empecilho:

- Método mais simples: ainda nas amostras coletadas das 63 imagens, verificar, para cada valor de saída, os seus respectivos valores de entrada, e calcular em seguida o seu valor esperado, ou seja, o centróide correspondente à sua distribuição (explicado na seção 5.3.1).

- Método complexo: utilizar o conceito de contexto. Neste, obtém-se um critério de desempate a partir da análise da vizinhança do pixel em questão (detalhamento na seção 5.3.3).

- Método complexo: contrução da Função de Transferência Segmentada Inversa (FTSI). É feito a seguimentação da função de transferência e inverte-se cada seguimento (explicado na seção 5.3.2.

\subsection{Ensaios para o segundo canal}

Após realizar todas essas etapas usando a impressora modelo HP LaserJet 4250dtn (impressora 1, vide anexo I.1.1), realizamos também nossa análise em outra impressora, utilizando o mesmo scanner.

A segunda impressora escolhida foi o modelo HP color LaseJet 4650 (impressora 2, vide anexo I.1.2), que é a laser e colorida. A diferença do procedimento adotado para esta foi unicamente o número de imagens submetidas ao processo, apenas 5. Para compensar o número menor de imagens utilizadas, geramos imagens maiores (somente $256 \times 256$ ), o que proporcionou o mesmo número de amostras, 1280 para cada um dos 256 níveis de cinza. O canal print-scan composto por esta impressora também é composto pelo mesmo scanner, HP ScanJet 3570c (scanner 1, vide anexo I.1.3), do primeiro canal. 


\section{Capítulo 5}

\section{Corretor Geométrico e de Tonalidade}

\subsection{Introdução}

A imagem escaneada sem tratamento não permite uma recuperação de cores satisfatória. Como a informação de cor está na textura, a distorção geométrica e a distorção do nível de cinza dos elementos da textura influenciam diretamente no resultado final. Portanto, é necessário que se faça um tratamento prévio da figura, onde se pretende corrigir ao máximo a distorção geométrica (seção 5.2) e de tonalidade (seção 5.3) dos elementos da textura da imagem.

\subsection{Corretor Geométrico por transformada afim}

O corretor geométrico proposto neste trabalho utiliza a transformada afim como base. Outros métodos poderiam ser utilizados, no entanto, o método por transformada afim foi escolhido devido ao fato de ser mais robusto, produzir resultados satisfatórios, e não incorrer em custo elevado de processamento computacional. Nas seções posteriores, iremos tratar de vários elementos necessários à aplicação do Corretor Geométrico.

A importância do método será avaliada na seção 5.2.1 e seu embasamento teórico da transformada Afim na seção 5.2.2. Outros pontos estratégicos como o problema de detecção das bordas (seção 5.2.3) e o critério de seleção de pixels para construção da imagem corrigida (seção 5.2.4) serão vistos com um cuidado maior.

\subsubsection{Importância do Corretor Geométrico na Recuperação das Cores}

Para que a recuperação das cores nas imagens tenham êxito, é necessário retirar a inclinação inserida durante o processo de impressão e o processo de digitalização. Mesmo que se tenha muito cuidado ao se colocar a folha na bandeja da impressora e sobre a superfície do scanner, na prática é inevitável a presença de algum grau inclinação, devendo este ser retirado por meio de software corretor. 

(a) (b) (cld) (e) (f)

Figura 5.1: Efeito da rotação no processo de recuperar de cores: (a) 0 grau, (b) 0,1 grau, (c) 0,2 grau, (d) 0,5 grau, (e) 1 grau, (f) 10 graus

A Fig. 5.1 apresenta imagens que foram rotacionadas e depois recuperadas. Como pode ser visto, houve problemas na aplicação do algorítimo de recuperação de cores.

\subsubsection{Transformada Afim}

A transformada afim consiste em um método no qual podemos mapear pontos entre dois planos. No nosso caso, um dos planos é a imagem obtida do escaneamento e o outro plano é a imagem construída pelo corretor, que age como uma referência ou molde para a correção. Ao mapear um determinado número de pixels da imagem escaneada para a região de um pixel na imagem referência, é feita correção da dimensão, da inclinação e o do deslocamento vertical e horizontal da imagem escaneada.

A determinação da matriz da transformada afim necessita de pelo menos três pares de pontos correspondentes. Dois pontos são candidatos a par de pontos correspondentes desde que:

- Um ponto $x$ represente o mapeamento de um ponto $x^{\prime}$ no plano oposto, e vice-versa.

- Não pertença a uma linha que una outros dois pontos utilizados.

Devido à dificuldade de se relacionar pontos no interior das figuras, foram escolhidos como pontos correspondentes, as quinas das imagens referência e escaneada. Para aumentar a precisão e confiabilidade dos cálculos, foram utilizadas as quatro quinas de cada imagem. O procedimento de localização dos pontos é descrito na secção 5.2.3.

Para que possamos processeguir o trabalho, devemos fazer algumas definições que possibilitaram eliminar possíveis desentendimentos. As matrizes básicas são:

- Ref, a matriz com localização das quinas da imagem referência.

- Scan, a matriz com localização das quinas da imagem escaneada.

- Offset, a matriz com a localização da ponto referência na imagem escaneada.

- $T_{a f i m}$, a matriz da transformada afim.

Expandindo as referidas matrizes, temos:

$$
\operatorname{Ref}=\left[\begin{array}{llll}
x_{0} & x_{1} & x_{2} & x_{3} \\
y_{0} & y_{1} & y_{2} & y_{3}
\end{array}\right]
$$




$$
\begin{gathered}
\text { Scan }=\left[\begin{array}{cccc}
x_{0}^{\prime} & x_{1}^{\prime} & x_{2}^{\prime} & x_{3}^{\prime} \\
y_{0}^{\prime} & y_{1}^{\prime} & y_{2}^{\prime} & y_{3}^{\prime}
\end{array}\right] \\
\text { Offset }=\left[\begin{array}{llll}
e & e & e & e \\
f & f & f & f
\end{array}\right] \\
T_{\text {afim }}=\left[\begin{array}{ll}
a & b \\
c & d
\end{array}\right]
\end{gathered}
$$

A expressão que relaciona as coordenadas da imagem referência e escaneada é apresentada a seguir:

$$
\operatorname{Re}_{2 \times 4}=T_{\text {afim } 2 \times 2} \times\left(\operatorname{Scan}_{2 \times 4}-\text { Off }_{\text {set }} \text { }_{2 \times 4}\right)
$$

A princípio deveria ser utilizado uma segunda Mariz Offset no lado esquerdo da expressão 5.5 diminuindo $R e f$, no entanto, escolhemos como ponto referência a quina superior esquerda das imagens. Por conta desta escolha, a Mariz Offset que entra no lado esquerdo é composta inteiramente de zeros, o que possibilita sua eliminação da expressão.

A fim de melhorar a visibilidade das manipulações algébricas, façamos:

$$
\begin{aligned}
& B_{2 \times 4}=\left(\operatorname{Scan}_{2 \times 4}-\text { Offset } \text { se4 }_{2 \times 4}\right) \\
& R e f_{2 \times 4}=T_{\text {afim } 2 \times 2} \times B_{2 \times 4}
\end{aligned}
$$

Tendo $B$ como a Mariz das coordenadas da imagem escaneada, já retirado o offset, e $B^{p i n v}$ sua pseudo-inversa:

$$
B_{2 \times 4}^{\text {pinv }}=B_{4 \times 2}^{\prime} \times\left(B_{2 \times 4} \times B_{4 \times 2}^{\prime}\right)^{-1}
$$

Portanto:

$$
\begin{gathered}
R e f_{2 \times 4}=T_{\text {afim } 2 \times 2} \times B_{2 \times 4} \\
R e f_{2 \times 4} \times B_{2 \times 4}^{\text {pinv }}=T_{\text {afim } 2 \times 2} \times B_{2 \times 4} \times B_{2 \times 4}^{p i n v} \\
R e f_{2 \times 4} \times B_{2 \times 4}^{\text {pinv }}=T_{\text {afim } 2 \times 2} \times\left(B_{2 \times 4} \times B_{2 \times 4}^{\text {pinv }}\right) \\
\operatorname{Re}_{2 \times 4} \times B_{2 \times 4}^{\text {pinv }}=T_{\text {afim } 2 \times 2} \times I_{2 \times 2}
\end{gathered}
$$

Desta forma, chegamos a uma expressão que possibilita o calculo da transformada afim apartir dos pontos referêntes as quinas da imagem escaneada e referência:

$$
T_{\text {afim } 2 \times 2}=\operatorname{Ref}_{2 \times 4} \times\left(B_{4 \times 2}^{\prime} \times\left(B_{2 \times 4} \times B_{4 \times 2}^{\prime}\right)^{-1}\right)
$$


Neste trabalho, assumiu-se como referencia a quina superior esquerda das imagens, portanto:

$$
\text { Offset }=\left[\begin{array}{cccc}
x_{0}^{\prime} & x_{0}^{\prime} & x_{0}^{\prime} & x_{0}^{\prime} \\
y_{0}^{\prime} & y_{0}^{\prime} & y_{0}^{\prime} & y_{0}^{\prime}
\end{array}\right]
$$

Para que se possa visualizar melhor o que será feito pelo software Corretor Geométrico, façamos como exemplo o mapeamento de apenas um pixel. Utilizando o que já foi desenvolvido anteriormente, temos assim:

$$
\left[\begin{array}{ll}
x & y
\end{array}\right]=T_{\text {afim } 2 \times 2} \times\left(\left[\begin{array}{ll}
x^{\prime} & y^{\prime}
\end{array}\right]-\left[\begin{array}{ll}
x_{0}^{\prime} & y_{0}^{\prime}
\end{array}\right]\right)
$$

Uma vez de posse da transformada afim, pode-se utilizar a Equação 5.15 para transportar um ponto de uma imagem a outra.

\subsubsection{Mapeamento das Bordas da Figura}

Como foi visto na seção 5.2.2, o cálculo da transformada afim será efetuado a partir da localização das quatros quinas das imagens, escaneada e referência. A localização destes pontos na imagem referência é bastante simples, uma vez determinado o tamanho da imagem corrigida, os pontos são determinados automaticamente, como visto na Expressão 5.16.

$$
\text { Ref }=\left[\begin{array}{llrr}
0 & \text { largura } & \text { largura } & 0 \\
0 & 0 & \text { altura } & \text { altura }
\end{array}\right]
$$

Entretanto, a obtenção da localização das quinas da imagem escaneada não é trivial. A posição das quinas depende de diversos fatores, como:

- A agrupamento de folhas na bandeja da impressora.

- Posição exata sobre a lâmina do scanner.

- Resolução escolhida para digitalização.

- Resolução e redimensionamento para impressão.

- Seleção de área do papel para escaneamento.

- Velocidade de coleta de folhas na impressora.

A localização das quinas na imagem escaneada terá de ser feita por meio de um algoritmo computacional. Alguns métodos foram testados, sendo dois mais expressivos: o primeiro, deteç̧ão de borda e regressão linear; e o segundo, por valor de limiar(threshold). Após alguns testes, foi constatado o tempo excessivo necessário para se utilizar a detecção de bordas e regressão linear, levando a ser utilizado portanto, o método por valor de limiar.

O método por valor de limiar consiste em selecionar todos os pixels abaixo de um determinado valor, assumindo que as bordas da imagem estavam abaixo deste valor. O valor de threshold é 
Figura 5.2: Localização das quinas de uma imagem utilizando o método por valor de limiar

arbitrado a partir de um número razoável de experimentos. Como a construção de um software extremamente robusto foge ao escopo deste trabalho, foram feitos pequenos pingos de caneta nas quinas da imagem antes de ser escaneada. Tal medida não prejudica os resultados alcançados, uma vez que são desprezíveis junto ao tamanho da imagem e o objeto principal do trabalho é o modelamento do canal print-scan.

Uma vez selecionados os pixels abaixo do valor de threshold, é feito uma varredura dos pixels mais acima, abaixo e à direita e à esquerda, estando estre eles as quinas da imagem como pode ser visto na Fig. 5.2. Como os pixels têm valores discretos e limitados a uma área quadrada, algumas vezes ocorre a detecção de mais de um pixel na extremidade. Para estes casos, foi desenvolvido um critério de escolha que analisa o pixel mais adequado, de acordo com a rotação e o posicionamento dos pixels.

O ruído injetado pelo canal print-scan, embora seja considerável, não atrapalhou o funcionamento do corretor geométrico. Os pixels da parte externa da figura tem valor muito alto (geralmente tem cor branca), o que possibilita o ruído reduzir o valor da parte branca até o threshold. Nas quinas da imagem, mesmo que o ruído eleve o valor da região, a aplicação da caneta leva a uma tonalidade escura a tal ponto que mesmo sobe ruído, o threshold não é superado.

\subsubsection{Critério de Seleção de Pixels}

Ao mapear os limites de um pixel da imagem referência na imagem escaneada, temos uma região que contempla certo número de pixels. Como o escaneamento geralmente é feito com resolução elevada, o que diminui possíveis perdas por resolução de escaneamento, existe sempre mais de um pixel com área compreendido pela área mapeada. Para decidir quais pixels serão usados, e em quais proporções, temos as seguintes alternativas:

- Utilizar os pixels cujo centro pertence à área mapeada.

- Utilizar todos os pixels com alguma área presente na região, sem ponderação.

- Utilizar todos os pixels com alguma área presente na região, usando a área pertencente como fator de ponderação.

Sem dúvida o melhor resultado é obtido pelo último método, no entanto, este se mostrou muito pesado; na seção 6.1 será mostrado que o primeiro método apresenta um desempenho aceitável, logo optamos por ele. O motivo pelo qual este fato ocorre é a dimensão muitas vezes maior obtida pela imagem escaneada frente a original. Na Tabela 5.1 é ilustrado a dimensão que uma imagem de 512 x512 pixels toma após ser impressa com 600 dpi e escaneada com certa resolução. 
Tabela 5.1: Dimensão de imagem resultante de cada resolução de escaneamento

\begin{tabular}{|c|c|c|}
\hline $\begin{array}{c}\text { Resolução de } \\
\text { Escaneamento }\end{array}$ & $\begin{array}{c}\text { Dimensão da Imagem } \\
(\text { pixels } \times \text { pixels })\end{array}$ & $\begin{array}{c}\text { Espaço Ocupado } \\
(\text { em MBytes })\end{array}$ \\
\hline $\mathbf{6 0 0}$ dpi & $1676 \times 1650$ & 2,63 \\
\hline 1200 dpi & $338 \times 3300$ & 10,66 \\
\hline $\mathbf{2 4 0 0}$ dpi & $6952 \times 6880$ & 45,61 \\
\hline $\mathbf{3 6 0 0}$ dpi & $10248 \times 10140$ & 99,10 \\
\hline 4800 dpi & $13408 \times 13200$ & 168,78 \\
\hline
\end{tabular}

\subsection{Corretor Misto de Tonalidade}

Além da distorção geométrica, existe também a distorção de tonalidade, que pode ser representada por uma função de Transferência (seção 5.3.1) e pelo ruído adicionado pelo canal print-scan. O ruído adicionado tem características estocásticas, o que não permite sua previsão, restando seu modelamento. Embora seja possível retirar parte do ruído adicionado, tal procedimento implica em perda de informação da imagem. A distorção de tonalidade, no entanto, pode ser modelada e a partir de uma função de transferência inversa, atenuar seu efeito na imagem em questão.

Com esse objetivo, deve-se utilizar as informações obtidas pela função de transferência e aplicar a função de transferência inversa na imagem corrigida. No entanto, ao se analisar as funções de transferências obtidas para os dois canais estudados, verifica-se que elas não são injetoras, isto é, mais de um valor de entrada correspondem a uma mesma saída, e nem sobrejetoras, onde o conjunto imagem (valores observados na saída) não preenche todo o conjunto do contradomínio (todos os valores possíveis de saída, no caso de 0 a 255).

Esta última característica pode ser facilmente contornada atribuindo-se o valor correspondente ao valor de saída mais próximo. Por exemplo, caso seja verificado um valor de saída 59, vemos que, pelas funções de transferência presentes nas Figs. 6.18 e 6.21, não há valores correspondentes de entrada; o menor valor de saída que possui correspondente na entrada é o valor 66 no primeiro canal e 61 no segundo canal, então, aproximar-se-ia a entrada correspondente ao 59 como sendo a entrada correspondente ao 66 .

Analisando as características verificadas na seção anterior, conclui-se que tal aproximação seria razoável, pois o menor valor obtido no espaço de amostras do primeiro canal foi 55 , e no segundo canal 52.

Por sua vez, a característica de não ser injetora é um pouco mais complicada de solucionar. Até mesmo se fossem utilizadas as curvas obtidas pelas regressões lineares a função não seria injetora, pois ao aproximar os valores obtidos pelas equações 6.3 e 6.5, mais de uma entrada seriam mapeadas para uma mesma saída.

Logo, conclui-se que a função de transferência do canal print-scan é não inversível. Por outro lado, é possível construir métodos para estimar os valores dos pixels da imagem de entrada a partir da imagem de saída. Desenvolvemos três métodos que realizam tal estimativa, as explicações de cada um seguem nas três subseções desta seção. 


\subsubsection{Função de Transferência saída-entrada pelo método do centróide}

O primeiro método desenvolvido, para mapear os valores da imagem impressa-escaneada e processada para valores que sejam próximos aos da imagem original, utilizou o conceito de centróide.

Para se calcular a função de transferência na seção 6.3, calculamos o centróide da distribuição das 1280 amostras para cada valor de entrada. Estimou-se, assim, o valor mais provável de saída para cada valor de entrada. A mesma idéia pode ser aplicada para obter o valor de entrada, mais provável, correspondente a cada saída.

A partir dos espaços de distribuições de amostras ilustrados nas Figs. 6.10 e 6.16, correspondentes aos dois canais estudados, calculamos o centróide das entradas possíveis para cada valor de saída. Obtivemos então a função de transferência saída-entrada para os dois canais print-scan em estudo. Um detalhe importante de se mencionar é que, apesar de essa função realizar o mapeamento saída-entrada, ela não pode ser chamada de "função de transferência inversa"' pois já vimos anteriormente que a função de transferência dos canais de impressão e escaneamento são não inversíveis. Comparando a Figs. 6.14 com a Fig. 6.22(a), e a Fig. 6.17 com a Fig. 6.22(b), verifica-se que realmente elas não se aproximam de serem mutuamente inversas. Para facilitar a aplicação dessa função sobre a imagem impressa-escaneada e corrigida, realizamos a regressão polinomial de quarto grau para se achar equações analíticas que as descrevam.

\subsubsection{Função de Transferência Segmentada Inversa}

A Função de Transferência obtida na seção 5.3.1 não é bijetora, não permitindo a obtenção da transformada inversa diretamente. Para contornar tal problema, dividimos a função de transferência em três partes:

- Faixa A: Faixa bijetora, inversão permitida.

- Faixa B: Utilização para baixos valores.

- Faixa C: Utilização para altos valores.

Das três regiões descritas, a mais simples é a região A. Nesta região não existe ambigüidade, sendo que para um valor da imagem escaneada nesta faixa, existe apenas um valor correspondente na imagem Original. No entanto, como o polinômio gerador da curva não é inversível, utilizamos o seguinte artifício:

1. Calcula-se a curva da Função de Transferência com número elevado de elementos, de 100 a 1000 vezes maior.

2. Constrói-se um vetor com 256 elementos, um para cada valor de cor possível.

3. Procura-se na curva, entre os valores de 'y', valor referente a uma cor do vetor de 2.

4. O procedimento é feito para toda a região conde a curva é bijetora, região A. 
A construção da transformada inversa nas regiões B e C segue o mesmo raciocínio anterior, para cada uma é construído um vetor de cores, sendo que para essas duas regiões, as cores para onde elas são definidas são conflitantes.

Na maior parte das imagens que circulam no meio digital, a concentração de pixels está no meio da faixa de valores possíveis, neste caso, região A e C. A região B contempla uma parcela pequena de pixels, sendo considerável apenas nas imagens mais escuras. Assim sendo, por padrão será utilizado a curva obtida de $\mathrm{A}$ e de $\mathrm{C}$ como função de transferência inversa. A região $\mathrm{B}$ será usada apenas se existir fator que a justifique, no caso, a análise do contexto do pixel problemático.

Ainda existe outro elemento a ser observado, depois da regressão feita, alguns pontos na imagem poderão estar abaixo da curva de transferência, não sendo contemplada pela função de transferência inversa. Para estes pontos, é arbitrado o menor valor da função de transferência, ou em outras palavras, a posição para a qual a curva de regressão tem o mínimo local.

A Fig. 5.3 ilustra as regiões A, B e C da função de transferência e da função de transferência inversa. 

(a) $\quad(b) c) \quad(d)$

Figura 5.3: Comparação entre a função de transferência e a função de transferência segmentada inversa (FTSI) do canal print-scan:(a) e (c) função de transfência, (b) e (d) FTSI.

\subsubsection{Contexto como critério de não Ambiguidade da Função de Transferência Inversa}

Como dito na seção 5.3.2, a região só deverá ser utilizada caso exista um parâmetro que justifique sua utilização. Um pixel na imagem escaneada e corrigida geometricamente que tenha valor na região problemática correspondente a $\mathrm{B}$ e $\mathrm{C}$, tem maior probabilidade de pertencer a $\mathrm{C}$.

Para que se possa utilizar a região $\mathrm{B}$, analisa-se o contexto dos pixels da faixa problemática. Tomam-se blocos de $3 \times 3$ e $5 \times 5$ centrados em cada pixel da região em questão. Utiliza-se a função de transferência inversa $\mathrm{A}+\mathrm{C}$ (situação para imagem mais clara) e $\mathrm{A}+\mathrm{B}$ (situação para imagens mais escuras), e então é calculado o desvio da região ao redor do próprio pixel.

A princípio, mesmo que o ruído adicionado pelo canal possa levar o pixel a um valor longe do corretor, sua vizinhança não seria afetada da mesma forma, o que permitiria concluir sobre sua origem. Resumindo, se o pixel é problemático, existindo dois valores possíveis para este, toma-se o valor mais escuro se a vizinhança for escura, e o mais claro, se a vizinhança for clara.

No entanto, não foi possível observar um padrão confiável para o contexto. Não existe um valor fixo para o desvio onde se possa discernir entre a região $\mathrm{B}$ e $\mathrm{C}$. A definição entre o desvio de $\mathrm{A}+\mathrm{C}$ e $\mathrm{A}+\mathrm{B}$, assim como sua razão também não ofereceram parâmetros suficientes para a utilização do contexto.

A Fig. 5.4 mostra como se comporta o contexto em uma imagem em particular, no caso, imagem Barbara. A primeira região, tracejada em preto (de 0 a 11), corresponde à área para onde a região B mapeia. A segunda região, tracejada em vermelho (de 26 a 61), corresponde à área para onde C mapeia. Tanto em (a) quanto em (b) é possível observar que o erro gerado pela utilização de $\mathrm{C}$ não é menor que o da utilização de $\mathrm{B}$, para toda a região $\mathrm{C}$ que compreende de 26 a 61 . Em (c) e em (d) não existe padrão a ser seguindo como, por exemplo, que diferença menor que zero permite utilizar a região B.

\section{(a) $\quad(\mathrm{b}) \mathrm{c}$ ) (d)}

Figura 5.4: Análise do Contexto para Imagem Barbara, onde o desvio da vizinhança é comparado para janelas de 3x3 e 5x5. O Desvio das janelas de 3x3(a) e 5x5(b) é obtido da aplicação da FTSI composta dos segmentos $\mathrm{A}+\mathrm{b}$ e $\mathrm{A}+\mathrm{C}$. O desvio entre as duas composições de segmentos para FTSI são comparadas pela razão entre elas(c), e pela diferença(d) 


\section{Capítulo 6}

\section{Resultados}

\subsection{Validação do Corretor geométrico}

Após a obtenção do código que executa a detecção de bordas e a transformada afim, chega-se a uma imagem corrigida geometricamente. Esta imagem ainda apresenta distorções advindas do canal print-scan, como a distorção de tonalidade e ruído aleatório, e junto a eles, o erro inerente à aproximação realizada pelo código da transformada afim.

Como o próprio Corretor geométrico insere um pequeno nível de distorção na imagem impressa e escaneada, se torna conveniente mensurar o desempenho do código e a influência do ruído sobre o processo. Para tal, é construído um código em MatLab que simula a distorção geométrica do canal print-scan, aumentando a imagem em dez vezes o seu tamanho original e a rotacionando em dois graus. Feita a simulação, a imagem é passada pelo corretor geométrico para então ser analisada.

Caso o código corretor fosse ideal, a imagem simulada/corrigida deveria ser exatamente igual à original. Com isso, os desvios verificados nesse teste podem ser atribuídos ao código corretor. Para realizar os testes, escolhemos três imagens tradicionais na área de processamento de imagem: Baboon, Barbara e Lena. A Fig. 6.1 ilustra as distribuições dos desvios.

Observa-se que a distribuição dos desvios possui a forma Gaussiana centrada em zero e é muito estreita, indicando que os desvios encontram-se bem próximos a zero. Para melhorar a visualização do significado dessa distribuição, construímos a Tabela 6.1, que indica a porcentagem do erro que está concentrada em uma determinada faixa, ou valor no caso do zero.

Mais da metade dos pixels das três figuras simuladas/corrigidas apresentaram erro menor ou igual a dois e os valores das médias dos desvios foram relativamente baixos. Apesar dos baixos valores de erros apresentados, idealmente, eles deveriam ser zero.

$(6)$

Figura 6.1: Distribuições dos desvios entre a imagem simulada/corrigida e a imagem original:(a) Imagem Baboon, (b) Lena, (c) Barbara 
Tabela 6.1: Porcentagem do erro do desvio concentrada em uma dada faixa (ou valor)

\begin{tabular}{|c|c|c|c|}
\hline $\begin{array}{c}\text { Faixa de } \\
\text { erro por Imagem }\end{array}$ & Baboon & Barbara & Lena \\
\hline 0 & $14,04 \%$ & $19,99 \%$ & $13,90 \%$ \\
\hline-1 a 1 & $38,19 \%$ & $51,32 \%$ & $36,87 \%$ \\
\hline-2 a 2 & $55,70 \%$ & $69,57 \%$ & $54,06 \%$ \\
\hline-3 a 3 & $68,32 \%$ & $80,17 \%$ & $67,98 \%$ \\
\hline-4 a 4 & $77,43 \%$ & $86,67 \%$ & $79,09 \%$ \\
\hline-5 a 5 & $84,06 \%$ & $90,90 \%$ & $86,82 \%$ \\
\hline $\begin{array}{c}\text { Média dos desvios } \\
\text { absolutos }\end{array}$ & 3,01 & 2,23 & 2,83 \\
\hline
\end{tabular}

Ao processar a imagem através do corretor geométrico é verificada a precisão, imagem por imagem, da deteç̧ão das quinas, e por conseqüência das bordas. Em todos os casos, as quinas detectadas coincidiram com as quinas da imagem, logo, o ruído aferido é resultado da aproximação realizada pelo código ao determinar o valor do pixel da imagem corrigida.

Figura 6.2: Ilustração da área mapeada na imagem escaneada pela transformada afim. O valor do pixel na imagem corrigida pode ser determinado pela média, ponderada pela área do pixel contida na área mapeada, dos pixels que compõem essa área

Conforme já mencionado na seção 5.2.4, o cálculo do pixel da imagem corrigida é obtido a partir dos pixels pertencentes à área aonde este é mapeado na imagem original. Esse mapeamento é ilustrado na Fig. 6.2. Observa-se que nem todos os pixels abrangidos por essa área estão inteiramente contidos nelas. Dentre os principais motivos para não consideração da parte fracionária dos pixels, responsáveis pelo ruído agregado, estão o crescimento exagerado da complexidade do código, do tempo de processamento e a pouca expressividade da distorção, como poderá ser visto adiante.

A aplicação principal para qual este trabalho está sendo desenvolvido é a recuperação de cores armazenadas em textura, aplicação melhor explicada na seção 2.6. Para verificar se o nível de ruído inserido pelo código compromete ou não a detecção de cores, é recuperada a cor da imagem simulada/corrigida e é feita a comparação com a imagem colorida original.

Ao analisar a Fig. 6.3, verifica-se que as cores das imagens recuperadas se apresentam com saturação menor que a original. Contudo, observa-se que as cores recuperadas são fiéis às originais e, visualmente, exibem grande semelhança.

Logo se conclui que, apesar de inserir um pequeno nível de ruído no processo, o código corretor geométrico possui desempenho suficiente para a aplicação desejada. 


\subsection{Imagem Corrigida Geometricamente e a Recuperação De Suas Cores}

Confirmada a qualidade do código do corretor geométrico, pode-se, agora, comparar a imagem corrigida com a original. Ainda não será estabelecida a função de transferência do canal, uma vez que será, primeiramente, calculado o desvio provocado pelo código e seu reflexo na recuperação das cores.

Para a realização dos testes foram utilizadas as mesmas imagens da seção anterior e em duas impressoras diferentes, a impressora 1 (modelo laser monocromática HP LaserJet 4250 dtn, vide anexo I.1.1) e a impressora 2 (modelo laser colorida HP color LaserJet 4650, vide anexo I.1.2).

A Fig. 6.4 mostra a imagem da Barbara após ser submetida ao processo de impressãoescaneamento e corretor geométrico para as duas impressoras utilizadas. Visualmente, pode-se observar que o canal print-scan alterou sensivelmente os valores dos pixels da imagem de entrada.

Para ilustrar melhor o desvio presente nas imagens processadas, foi calculado o módulo da diferença entre as imagens corrigidas e as originais, para então serem levantadas as respectivas distribuições de erros. 
Analisando as Figs 6.4 e 6.5, percebe-se que o valor do desvio é maior nos pontos onde os pixels da imagem original são mais escuro. Isso deve a uma característica do processo print-scan que será apresentada na próxima seção, segundo a qual, nenhum valor de amostra das imagens corrigidas se encontram abaixo de um determinado limiar. Para as duas impressoras em análise, este limiar é 53. Exemplificando, um pixel originalmente em zero na primeira impressora resultará em um desvio de pelo menos 55. Esse fenômeno é intrínseco ao canal print-scan, não possuindo relação com o código do corretor implementado.

As curvas com as distribuições dos erros estão na Fig. 6.6. A Tabela 6.2 resume seus principais parâmetros.

Tabela 6.2: Principais parâmetros das curvas de desvio resultantes do canal print-scan

\begin{tabular}{|c|c|c|c|}
\hline Impressora/Parâmetro & Moda & Variância & Média \\
\hline Impressora 1 & 11 & 202.78 & 15,54 \\
\hline Impressora 2 & 3 & 245.86 & 15,12 \\
\hline
\end{tabular}

Uma distribuição de erros desejada é aquela que está centrada mais próxima ao zero (ou no zero preferencialmente) e com um pequeno valor de variância. Apesar de a segunda curva estar centrada mais próxima ao zero, sua variância foi maior, resultando uma média de desvios muito próxima à primeira. Para efeitos de comparação, damos o exemplo de uma curva Gaussiana que representa um pequeno ruído: a curva de distribuição de desvios conjunta, obtida ao se somar as três curvas da Fig. 6.1, resultantes da imagem com efeitos geométricos print-scan simulados e corrigidos pelo código, que apresentou moda zero, variância 5.90 e média 2,69.

Vemos então que o canal de impressão e escaneamento realmente introduz uma alteração significativa nos valores dos pixels da imagem original, mesmo depois de corrigirmos as distorções geométricas. Uma forma melhor de se visualizar a influência deste canal na recuperação de cores, é realizar a própria recuperação de cores das imagens corrigidas. As Figs. 6.7, 6.8 e 6.9 ilustram as recuperações de cores das imagens Baboon, Lena e Barbara após passarem pelo canal print-scan e pelo código corretor.

Entre as seis imagens recuperadas, a Fig. 6.8(c) praticamente não apresentou recuperação de cor. A recuperação na Fig. 6.8(b) também obteve baixa qualidade, apesar das cores recuperadas lembrarem o padrão original. Por outro lado, as duas imagens recuperadas do baboon e as duas recuperadas da Barbara apresentaram resultados motivadores.

Nessas quatro imagens, podemos notar visualmente a semelhança entre as originais e as recuperadas. As imagens representadas na Fig. 6.7(b) e na Fig. 6.9(b) possuem cores mais vivas, contudo as representadas na Fig. 6.7(c) e na Fig. 6.9(c) foram mais fiéis à original. A palidez observada nestas duas últimas pode ser melhorada aplicando-se um pós-processamento de realce das cores, intensificando-as.

Considerando o alto nível de ruídos e distorções inseridos pelo canal print-scan, os resultados obtidos nessa etapa foram satisfatórios, uma vez que, a recuperação de cores de imagens impressas e escaneadas sem a aplicação do corretor geométrico, não alcançavam cores semelhantes às cores da imagem original. 


\subsection{Ensaios Para Determinar A Função De Transferência}

Apesar das imagens obtidas após a impressão, escaneamento e correção terem apresentado bons resultados, verifica-se que uma quantidade razoável de informação de cor foi perdida devido aos efeitos distorcivos do canal print-scan. Um modo de melhorar a recuperação de cores é determinar a função de transferência do canal de impressão e escaneamento, e em seguida, aplicar a função de transferência inversa sobre a imagem corrigida geometricamente.

Com o objetivo de determinar a função de transferência do canal impressão e escaneamento referente à Impressora 1 e o Scanner 1 (canal 1), adotamos o procedimento já mencionado no capítulo 5, segundo o qual realizamos o processo de impressão, escaneamento e correção geométrica para 63 imagens (de tamanhos variáveis). Aferimos os valores de saída e obtivemos 1280 amostras para cada um dos 256 níveis de cinza. Após a coletada das amostras, é construído o gráfico 3-D ilustrado na Fig. 6.10. Este gráfico representa os valores dos níveis de cinza de entrada e saída. A altura do gráfico informa quantas amostras tinham uma entrada $\mathrm{X}$ e resultaram em uma saída $\mathrm{Y}$.

Para cada valor de entrada, há uma distribuição de valores de saída em torno de um pico. A largura dessa distribuição varia ao longo do gráfico, e quanto mais estreita a base do gráfico, menor o erro apresentado. Para valores de entrada nas proximidades de 250, os valores de saída apresentam um alto nível de concentração em torno do pico. Outra característica que chama a nossa atenção é o deslocamento inicial observado nos valores de saída, onde não se observa nenhuma amostra abaixo de 53 .

A próxima etapa foi o cálculo da função de transferência. Esta pode ser calculada a partir do espaço de amostras ilustrado na Fig. 6.10. Esse cálculo deverá estimar o melhor valor dentro da faixa de valores de saída observados para cada valor de entrada. Com esse propósito, aplica-se a fórmula do centróide (Equação 4.1) para cada conjunto de amostras correspondentes a cada entrada. O resultado foi o gráfico ilustrado na Fig. 6.11.

A característica deslocamento inicial dos valores de saída observado no espaço de amostras, é reforçada ainda mais na função de transferência. Aqui, o menor valor de saída encontrado foi 66 . Como foi realizada uma estimativa de melhor valor, dentro de um conjunto de valores possíveis, achamos conveniente analisar o erro associado e essa estimativa. A curva mostrada na Fig. 6.12 é o histograma do desvio das amostras em relação aos valores estimados.

Observa-se que sua distribuição é estreita em relação ao pico, característica desejada para curvas de distribuições de erro. Para melhor compreender as informações contidas nesse gráfico, efetuamos uma regressão Gaussiana na curva do histograma e em seguida calculamos seus principais parâmetros. A equação obtida foi:

$$
r_{1}(x)=2,7 \cdot 10^{4} \cdot e^{\left(-\frac{x}{6,42}\right)^{2}}
$$

Normalizando:

$$
r n_{1}(x)=0.0915 \cdot e^{\left(-\frac{x}{6,42}\right)^{2}}
$$


A Tabela 6.3 apresenta os principais parâmetros da curva da Fig. 6.12.

Tabela 6.3: Principais características associadas ao histograma de desvios inerentes à função de transferência

\begin{tabular}{|l|l|l|l|l|}
\hline $\begin{array}{l}\text { Probabilidade de } \\
\text { acerto }(\text { Erro }=0)\end{array}$ & Moda & Variância & Média & $\begin{array}{l}\text { Média dos desvios } \\
\text { absolutos }\end{array}$ \\
\hline $9,15 \%$ & 0 & 20.61 & $-0.0007 \cong 0$ & 4,44 \\
\hline
\end{tabular}

Apesar do desvio igual a zero ser a moda (valor com maior freqüência) do histograma, da variância ser um valor relativamente pequeno e da estimativa através do centróide ser aquela que gera um menor erro, verifica-se que a probabilidade do valor estimado pela função de transferência ser exatamente o valor resultante do processo print-scan é pequena, 9,15\%. Este valor foi calculado dividindo-se a freqüência de desvio igual à zero pelo somatório das freqüências de -255 a 255 . Em média, a distância entre o pixel da imagem impressa-escaneada e corrigida e o estimado pela função de transferência será $4,44 \approx 4$.

A Equação 6.2 representa o ruído $\mathrm{r}(\mathrm{t})$ do modelo do canal print-scan apresentado na Fig. 3.2. O modelamento do ruído do canal de impressão e escaneamento possui três características fundamentais que determinam:

- Distribuição Gaussiana

- Centrado em zero

- Variância estreita, 4, 54

Conclui-se então que, apesar de possuir uma distribuição estreita e ser centrado em zero, o ruído inserido pelo canal print-scan compromete a recuperação precisa dos valores dos pixels da imagem original.

Deseja-se chegar a uma expressão analítica da função de transferência para se completar o modelamento do canal print-scan. Para tal, realizamos uma regressão polinomial na função da Fig. 6.14. O menor grau polinomial que proporcionou uma razoável aproximação foi o quarto.

A equação obtida da regressão polinomial foi:

$$
F T_{1}(x)=-4,9 \cdot 10^{-8} \cdot x^{4}+8,32 \cdot 10^{-6} \cdot x^{3}+0,0045 \cdot x^{2}-0,1254 \cdot x+66,4
$$

Observe que a equação acima quase sempre resultará em valores reais fracionários. Como a representação em níveis de cinza usa apenas números inteiros positivos, deve-se sempre aproximar o resultado na equação acima.

Outra possibilidade é que a função de transferência possa sofrer pequenas alterações devido às características da imagem original, como por exemplo, a taxa de variação dos valores dos pixels, tamanho de segmentos etc. Para observarmos se tal fenômeno acontece com o nosso modelo, verificamos qual a função de transferência correspondente ao processo ocorrido em três imagens: Baboon, Lena e Barbara. A Fig. 6.15 compara a função de transferência obtida pelas imagens em gradiente de tom (Fig. 6.11) e a função de transferência obtida pelas três imagens. 
Apesar de haver uma diferença considerável nos extremos:

$$
\operatorname{pixel}(\text { entrada })<40 \text { e pixel }(\text { entrada })>240
$$

As curvas estão bem próximas na maior parte se seus valores. Tem-se que levar em conta que, na curva em vermelho, o número de amostras utilizadas foi bem menor; muito provavelmente, se utilizássemos um número maior de imagens para determinar essa função de transferência, seus valores extremos se aproximariam mais da curva em azul.

Achamos conveniente realizar também o modelamento do canal de impressão e escaneamento composto pela Impressora 2 ( HP LaserJet 4650). O procedimento adotado foi o mesmo, com exceção de trocarmos quantidade de figuras impressas e escaneadas por tamanho das imagens de teste, resultando no mesmo número de amostras. A Fig. 6.16 mostra o espaço de amostras obtido para essa segunda impressora. 
Observa-se que seu formato geral se aproxima bastante daquele apresentado para a primeira impressora. O deslocamento inicial observado aqui também se aproximou ao do primeiro caso; no espaço da Fig. 6.16 não houve amostras com valores abaixo de 53.

A função de transferência estimada a partir do espaço de amostras acima e sua respectiva regressão polinomial (também de quarto grau) encontra-se na Fig. 6.17. A equação obtida pela regressão foi:

$$
F T_{2}(x)=-3.82 \cdot 10^{-8} \cdot x^{4}+8,54 \cdot 10^{-6} \cdot x^{3}+0,0033 \cdot x^{2}+0,0146 \cdot x+61.35
$$

Lembrando, novamente, que os valores resultantes da função acima devem ser arredondados para gerar uma saída dentro do domínio da representação em nível de cinza. O deslocamento inicial resultante dessa função de transferência foi 61 , aproximando-se do valor da primeira, 66 . A Fig. 6.18 compara a função de transferência obtida para a primeira impressora e a obtida pela segunda.

Analisando a Fig. 6.18, observa-se que as funções de transferência obtidas para as duas impressoras são muito parecidas e próximas entre si. Aparentemente este comportamento é um paradoxo, pois se verificou anteriormente que os resultados produzidos por ambas as impressoras possuem características distintas. Uma hipótese é que o grande diferencial entre os dois canais está no nível de ruído inserido por cada um. Para confirmá-la, verificamos o ruído inserido pelo canal composto pela segunda impressora. A Fig. 6.19 mostra o histograma dos desvios inerentes à sua função de transferência e sua respectiva regressão Gaussiana.

Visualmente, detecta-se que o histograma de desvios inerentes à função de transferência do canal composto pela segunda impressora 6.19 possui distribuição mais estreita que a primeira 6.12. Vejamos a função Gaussiana obtida pela regressão e seus parâmetros para podermos ter critérios mais objetivos de análise.

$$
r_{2}(x)=4,95 \cdot 10^{4} \cdot e^{\left(-\frac{x}{3,62}\right)^{2}}
$$

Normalizando:

$$
r n_{2}(x)=0.1721 \cdot e^{\left(-\frac{x}{3,62}\right)^{2}}
$$

A Tabela 6.4 apresenta os principais parâmetros da curva da Fig. 6.19.

Tabela 6.4: Principais características associadas ao histograma de desvios inerentes à função de transferência associada à segunda impressora

\begin{tabular}{|l|l|l|l|l|}
\hline $\begin{array}{l}\text { Probabilidade de } \\
\text { acerto }(\text { Erro }=0)\end{array}$ & Moda & Variância & Média & $\begin{array}{l}\text { Média dos desvios } \\
\text { absolutos }\end{array}$ \\
\hline $17,21 \%$ & 0 & 6.55 & $-0,0007 \cong 0$ & 2,2 \\
\hline
\end{tabular}

O coeficiente multiplicando a exponencial da Equação 6.6 foi bem superior ao dá Equação 6.1, ultrapassando-o em $83 \%$. A partir dessa informação, já poderíamos inferir que a probabilidade de o valor estimado ser exatamente o resultante do processo de impressão-escaneamento e correção, 
ou seja, a probabilidade do erro ser igual a zero, para essa segunda impressora seria maior que a primeira. Isso pôde ser verificado pelos cálculos dos parâmetros Tabela 6.4.

Verifica-se também que a variância apresentada pela curva, foi menor que a observada para o primeiro caso, indicando que a distribuição está mais concentrada em torno do pico (erro igual a zero), gerando uma expectativa de erro menor. A distância média dos valores apresentados na imagem corrigida geometricamente e o valor estimado pela função de transferência foi de 2,2, exatamente a metade do verificado para a primeira impressora.

Conclui-se, então, que o canal composto pela segunda impressora insere um ruído com nível menor que o da primeira impressora, inserido pelo canal.

Finalmente chegamos aos modelos que descrevem o comportamento dos dois canais print-scan estudados, caracterizados pela distorção geométrica, pela aplicação da função de transferência e pela inserção de um ruído com distribuição normal, vide Fig. 6.20 e 6.21 


\subsection{Aplicação Da Função De Transferência Inversa}

Como já mencionado na seção 5.3, há uma barreira ao se procurar aplicar as informações da função de transferência visando a correção da distorção de tonalidade através da construção de uma função de transferência inversa: a função de transferência não é bijetora. Os métodos adotados para solucionar esse problema estão expostos na referida seção, os resultados dos mesmo nas três subseções abaixo.

\subsubsection{Método do Centróide}

Conforme já explicado na seção 5.3.1, este método estima o valor de entrada correspondente a um dado valor de saída através do cálculo do centróide da distribuição de valores de entrada possíveis correspondentes. Também foi abordado na seção 5.3, que essa estimativa não pode ser chamada de função de transferência inversa. Logo a denominamos de Função de Transferência saída-entrada (FTSE).

A Fig. 6.22(a) ilustra a FTSE obtida para o canal composto pela impressora 1 e o scanner padrão (canal 1), e a Fig. 6.22(b) a FTSE obtida para o canal composto pela impressora 2 e o mesmo scannner (canal 2). Para facilitar a aplicação dessas funções sobre a imagem impressaescaneada e corrigida, realizamos a regressão polinomial de quarto grau para se achar equações que as descrevam. As respectivas equações seguem abaixo, onde a Equação 6.8 se refere o canal 1 e a 6.9 ao canal 2 :

$$
\begin{aligned}
& \operatorname{FTSE}_{1}(x)=3,898 \cdot 10^{-7} \cdot x^{4}-0,000216 \cdot x^{3}+0,0383 \cdot x^{2}-1,231 \cdot x+6,4 \\
& \operatorname{FTSE}_{2}(x)=3,97 \cdot 10^{-7} \cdot x^{4}-0,000224 \cdot x^{3}+0,0404 \cdot x^{2}-1,367 \cdot x+7,5
\end{aligned}
$$

As funções de transferência saída-entrada obtidas para os dois canais em estudo são muito semelhante. Porém, conforme se verificou para a função de transferência entrada-saída, espera-se que o ruído inerente à estimativa realizada pela função de transferência para o canal da impressora 1 seja consideravelmente maior do que a o canal da impressora 2.

Para se chegar ao modelamento do referido ruído, aferimos a distribuição de desvios das amostras em relação ao valor estimado pela função de transferência. As curvas obtidas e suas respectivas regressões Gaussianas encontram-se nas Figs 6.24(a) e (b).

As equações que descrevem as distribuições Gaussianas nas Figs. 6.24(a) e (b) são respectivamente:

$$
\begin{aligned}
& e_{1}(x)=1,77 \cdot 10^{4} \cdot e^{\left(-\frac{x}{9,86}\right)^{2}} \\
& e_{2}(x)=3,32 \cdot 10^{4} \cdot e^{\left(-\frac{x}{4,94}\right)^{2}}
\end{aligned}
$$


A Tabela 6.5 mostra os principais parâmetros das duas curvas Gaussianas acima.

Analisando a tabela acima, juntamente com as Figs. 6.24(a) e (b), verifica-se a expectativa já mencionada anteriormente: o ruído inserido pelo canal da segunda impressora é consideravelmente menor que o inserido pelo canal da primeira. Verifica-se, também, ao se comparar os parâmetros dos desvios inerentes à estimativa da função de transferência entrada-saída e os inerentes à estimação da função de transferência saída-entrada, que o ruído inerente a esta é superior a aquela.

Apesar de possuírem distribuições estreitas de desvio, observa-se que a probabilidade do valor estimado pela função de transferência saída-entrada ser exatamente o da imagem original é ainda pequena, 5,73\% para o primeiro canal e 10,82\% no segundo. Espera-se, então, que a imagem resultante da aplicação dessa função de transferência não produza uma melhora significante na qualidade da recuperação de cores. O melhor jeito de se verificar é aplicar a função e proceder à recuperação de cores. A Fig. 6.25 mostra o baboon antes e após o processamento da função de transferência para primeiro canal e a Fig. 6.26 para o segundo canal.

Realizamos a comparação entre as imagens antes e após serem processadas pela função de transferência saída-entrada com a imagem original. Escolhemos como exemplo a imagem Baboon, levantamos o histograma de distribuição de desvio e obtivemos as curvas das Figs. 6.27 e 6.28. A Tabela 6.5 mostra os principais parâmetros dessas curvas.

Analisando os dados da Tabela 6.5, verifica-se houve melhora na proximidades das imagens processadas em relação à original com a aplicação da função de transferência. A moda, que indica o valor em torno do qual a distribuição dos desvios se concentra se aproximou consideravelmente da origem no primeiro canal e a atingiu no segundo. A variância, que mede o grau de dispersão da distribuição, praticamente não se alterou no primeiro canal; já no segundo houve uma discreta melhora no grau de concentração. A média da distância dos valores das imagens processadas aos valores da imagem original teve redução de $12,5 \%$ e $15,2 \%$ respectivamente. 


\subsubsection{Aplicação da Função de Transferência Seguimentada Inversa}

A Função de Transferência Segmentada Inversa (FTSI) consiste basicamente na inversão ponto a ponto da Função de Transferência do canal. Como pode ser visto na Fig. 6.29, a região inferior da curva apresenta um intervalo onde a função não é bijetora, por tanto, a função de transferência será separada em três segmentos. A parte predominante e bem comportada é chamada de seguimento A, em azul. A parte conflitante é dividida em duas: B, a parte mais escura; C, a parte mais clara.

Em geral, as imagens que circulam no cotidiano têm seu espectro de cor concentrada no centro. Tal fato se explica devido à dificuldade da visão humana em diferenciar tons muito escuros e tons muito claros, confundindo-os com a cor preta e branca, respectivamente. A Tabela 6.10 demonstra a área compreendida por cada seguimento.

O seguimento A, que corresponde a maior porção da função de transferência do canal, abrange a maior parte dos pixels da figura, seguido da região compreendida pelo seguimento C. O seguimento B contempla a menor porção da figura, sendo esta a porção mais escura. É importante lembrar-se da dificuldade do tonner em representar tons muito escuros, uma vez que o tonner comum não é perfeitamente opaco, levando o seguimento B a apresentar um grande desvio, como pôde ser visto na Fig. 6.29.

A FTSI pode ser composta de diversos arranjos de seguimentos. Cada seguimento é aplicado somente sobre os pixels dentro de sua região, no entanto, os seguimentos B e C compreendem a mesma região, impedindo a utilização conjunta destes em um dado arranjo. Como podem vir a existir pontos abaixo da regressão da função de transferência do canal, e portanto, fora da área onde a FTSI é definida, é considerado como Extra o ganho advindo do arbitramento destes pixels com valor do menor ponto apresentado na função de transferência. Para que seja escolhido o melhor arranjo para a FTSI, foram feitos testes para os seguintes arranjos:

- Seguimento A apenas.

- Seguimento A e B.

- Seguimento A e C.

- Seguimento A e C e pontos fora da FTSI (Extra).

Para se ter um parâmetro de comparação entre os arranjos, foi escolhido o erro médio. A fim de se obter um cenário mais geral, foi aplicada, em três imagens, a FTSI com os arranjos descritos. A Tabela 6.7 apresenta os resultados obtidos para a impressora 1 e a Tabela 6.8 para a impressora 2 .

Como pode ser visto nas Tabelas 6.7 e 6.8, o arranjo que obteve o menor erro médio foi o arranjo composto pelos seguimentos $\mathrm{A}, \mathrm{C}$ e o arbitramento dos demais pontos abaixo da curva de regressão da função de transferência. Com ganhos que chegaram a 36,49\% de redução do erro da imagem sem a aplicação da FTSI, o arranjo escolhido será este.

Em todos os casos analisados, a utilização do arranjo composto por A e B, resultou em uma queda de desempenho tão grande que, em alguns casos, ultrapassava o ganho obtido pela utilização 
do seguimento A. Este resultado se deve ao fato do seguimento B mapear todos os pixels da região problemática para pixels muito escuros. Como a maioria dos pixels das imagens comuns estão situados no centro do espectro de cor, em uma parte mais clara, o ganho obtido pelo correto mapeamento dos pixels escuros é sobreposto com folga sobre o mapeamento incorreto dos pixels claros.

Para ilustrar o efeito ocorrido sobre as imagens após a aplicação da FTSI, são apresentados na Fig. 6.30 o comportamento da função de transferência individual de cada imagem, para cada arranjo proposto. Deve-se observar que a função de transferência do canal, utilizada para calcular a FTSI, foi obtida de uma imagem gradual que apresentava todas a 256 variações de cores da escala de cinza, todas com mesma proporção. 


\subsubsection{Método de análise pelo contexto}

A FTSI apresentada na seção 6.4.2 obteve grandes ganhos ao se utlizar o arranjo composto por A, C e o arbitramento dos pontos situados abaixo da regressão da função de transferência. No entanto, como é utilizado de forma indiscriminada o seguimento C, os pontos onde se deve utilizar o seguimento B, são erroneamente mapeados para parte mais clara, o que gera uma distorção. Como a proporção dos pixels a serem mapeados por B é muito menor que os pixels a serem mapeados por C, o ganho obtido pela utilização indiscriminada de C é justificada pelo ganho evidenciado.

Mesmo que a proporção de pontos que deveriam ser mapeados por B seja pequeno, ainda é possível se obter mais um ganho através da utilização correta deste seguimento. Para tanto, é proposta a análise do contexto dos pixels da região problemática, retirando da vizinhança, a informação da real identidade do pixel.

O método proposto consiste na aplicação da FTSI composta por A e C, e a composta por A e B, na vizinhança dos pixels da região problemática. Esta janela poderá ser de 3x3 ou 5x5. Em um primeiro momento será analisado mais a fundo a janela de $3 \times 3$.

Uma vez aplicado a FTSI na vizinhança de um pixel, é calculado o desvio médio entre o pixel central e os pixels da vizinhança. Para tanto, são obtidos dois desvios: um para FTSI composta de A e C, e outro para a FTSI composta de A e B. Como o seguimento C compreende a maior porção de pixels da região, este será utilizado por padrão, sendo usado o seguimento $\mathrm{B}$, somente quando o erro auferido por B for menor que certa fração do erro de C.

Para determinar qual a fração de $\mathrm{C}$ mais apropriada, foram realizados testes para frações que vão de $100 \%$ a 0\%, que representa a não utilização da FTSI composta de B. A Tabela 6.9 apresenta os resultados obtidos para a impressora 1 e a Tabela 6.10 apresenta os resultados para a impressora 2 .

Como pode ser percebida, a utilização do contexto não garantiu ganho em relação ao método da FTSI puro. Mesmo que em imagens muito escuras o método do contexto possa vir a apresentar ganho, este não ocorre para a aplicação proposta neste trabalho, que compreende imagens utilizadas no cotidiano, onde o espectro de freqüência se concentra no centro.

\subsection{Comparação entre os Corretores de Tonalidade Propostos}

Como já dito em seções anteriores, a aplicação que oferece os parâmetros de adequação do modelo proposto neste trabalho, é a recuperação de cores armazenadas em texturas. Para tanto, são comparados os parâmetros estatísticos de erro para as três imagens analisadas (Baboon, Lena e Barbara) e a análise subjetiva da recuperação de cores.

Como visto nas Tabelas 6.11 e 6.12, o método que aucansou o melhor resultado foi o FTSI, seguido pelo FSTE. O método do contexto obteve o pior resultado, como já previsto na seção 6.4.3. As Figs. que vão de 6.31 a 6.31 , ilustram a diferença entre a utilização de cada método.

Figura 6.34: do canal pr geometricam 


$$
\begin{array}{llll}
\text { (a) } & (\mathrm{b}(\mathrm{c}) & (\mathrm{d}) \mathrm{e}) & (\mathrm{f}) \\
\text { Ori- } & \text { R@ri- } & \text { R@ri- } & \text { Re- } \\
\text { gi- } & \text { cugi- } & \text { cugi- } & \text { cu- } \\
\text { nal peral } & \text { pełal } & \text { pe- } \\
& \text { rada } & \text { rada } & \text { rada }
\end{array}
$$

Figura 6.3: Imagens recuperadas após simulação e posterior correção geométrica
(a) $(b) c)$
Ori- Intim-
gi- proses-
nal sorara
Tex- 12
tu-
ri-
zada

Figura 6.4: Correção da imagem após a impressão e o escaneamento para os dois canais estudados.
(a) (b)
Im- Im-
pres- pres-
sora sora
12

Figura 6.5: Diferença absoluta entre a imagem corrigida e a original
(a) (b)
Im- Im-
pres- pres-
sora sora
12

Figura 6.6: Distribuição dos desvios entre a imagem corrigida e a imagem original, resultante do canal print-scan, para imagem Barbara.

$$
\begin{aligned}
& (a) b(c) \\
& \text { CRete- } \\
& \text { locueu- } \\
& \text { riфқар e- } \\
& \text { Oriardada } \\
& \text { giłnfin- } \\
& \text { naproses- } \\
& \text { sorara } \\
& 12
\end{aligned}
$$

Figura 6.7: Recuperação da cor da Imagem Baboon após transmiti-la via canal print-scan 1 (b) e $2(\mathrm{c})$. 


$\begin{array}{lll}\text { (a) } & \text { (b) } & \text { (c) } \\ \text { Co- } & \text { Re- } & \text { Re- } \\ \text { lo- } & \text { cu- } & \text { cu- } \\ \text { rida } & \text { pe- } & \text { pe- } \\ \text { Ori- } & \text { rada } & \text { rada } \\ \text { gi- } & \text { Im- } & \text { Im- } \\ \text { nal } & \text { pres- } & \text { pres- } \\ & \text { sora } & \text { sora } \\ & 1 & 2\end{array}$

Figura 6.8: Recuperação da cor da Imagem Lena após transmiti-la via canal print-scan 1 (b) e 2 (c)

$$
\begin{aligned}
& (a) b(b) \\
& \text { CRrfe- } \\
& \text { loeveu- } \\
& \text { riprepe- } \\
& \text { Oräackada } \\
& \text { giłnimm- } \\
& \text { naplposes- } \\
& \text { sorara } \\
& 12
\end{aligned}
$$

Figura 6.9: Recuperação da cor da Imagem Barbara após transmiti-la via canal print-scan 1 (b) e $2(\mathrm{c})$.

Figura 6.10: Representação do número de eventos para cada par entrada, saída utilizando-se a impressora 1.

Figura 6.11: Função de Transferência obtida para canal print-scan, usando a impressora 1 e o scanner padrão.

Figura 6.12: Histograma dos desvio entre as amostras e o valor estimado pela função de transferência do canal 1

Figura 6.13: Regressão Gaussiana realizada na distribuição do ruído associado ao canal 1

Figura 6.14: Regressão polinomial da função de transferência do canal 1

Figura 6.15: Comparação entre a função de transferência determinada pelo modelo (azul) e a função de transferência correspondente de três imagens tradicionais (vermelho).

Figura 6.16: Representação do número de eventos para cada par (entrada, saída) usando a Impressora 2

Figura 6.17: Função de transferência obtida utilizando-se a segunda impressora (curva azul) e sua respectiva regressão polinomial.

Figura 6.18: Comparação entre as funções de Transferência obtidas para as duas impressoras: Curva azul - Impressora 1; Curva vermelha - Impressora 2 
Figura 6.19: Distribuição do ruído associado ao canal 2 e sua respectiva regressão Gaussiana.

Figura 6.20: Modelo obtido para o canal print-scan composto pela Impressora 1 


\section{Capítulo 7}

\section{Conclusões}

Nesse trabalho final de graduação, realizou-se o modelamento do canal de impressão e escaneamento e a implementação de certas ferramentas de processamento de imagens que realizam a correção da distorção geométrica e a correção da distorção de tonalidade sofridas pela imagem ao passarem pelo canal print-scan.

O primeiro resultado relevante obtido foi a implementação da transformada afim, responsável pela correção geométrica da imagem impressa e escaneada. No código construído em linguagem $\mathrm{C}++$, optamos pela utilização de um método simplificado para a realização dessa ferramenta, cujas aproximações resultam em uma distribuição de erro pequena.

A obtenção dessa ferramenta proporcionou um avanço considerável do projeto, pois propiciou a obtenção de imagens impressas-escaneadas e corrigidas com a mesma disposição geométrica que as imagens originais, possibilitando a recuperação de cores das imagens corrigidas, a determinação da função de transferência do canal print-scan e o modelamento do ruído inserido por este canal. Foram analisados e modelados dois canais de impressão e escaneamento, utilizando duas impressoras e um scanner.

O método foi aplicado para recuperação de cores mapeadas em texturas para impressão monocromática. O nível de recuperação das cores das imagens corrigidas foi motivador, pois as imagens coloridas recuperadas representaram de forma relativamente fiel o padrão de cores da imagem colorida original. Apesar de mais pálidas, as imagens recuperadas oriundas do canal 2 apresentam-se mais precisas na representação das cores.

Para cada canal, determinou-se a função de transferência e o modelamento do ruído inerente. Os canais 1 e 2 apresentaram funções de transferência muito próximas entre si e também uma característica curiosa: Nenhum pixel da imagem impressa-escaneada e corrigida apresentou valor abaixo de 53 .

Há a possibilidade de se usar as informações obtidas pelo modelamento da função de transferência do canal visando a atenuar ao máximo sua influência na recuperação de cores. Para isso busca-se a aplicação da função de transferência inversa sobre a imagem corrigida. Contudo, a função de transferência do canal de impressão e escaneamento não é bijetora e, por conseguinte, não é inversível. Logo não é possível a estimação de uma função de transferência inversa rigorosamente 
falando. O que é possível é a construção de métodos de estimativas, que realizam um mapeamento de cada valor do espaço de saída para valores no espaço de entrada, buscando aproximar-se ao máximo a imagem processada da original.

Com esse objetivo, implementamos três métodos diferentes para realizar o mapeamento saídaentrada: 1) Método de aplicação dos centróides; 2) Função de Transferência Segmentada Inversa e 3) Método de análise pelo contexto (vizinhança) da imagem.

Utilizando-se o método do centróide, obteve-se uma melhora visualmente perceptível na recuperação de cores. As cores recuperadas ficaram mais vivas e o nível de detalhamento da imagem resultante também melhorou. O método da Função de Transferência Segmentada Inversa gerou resultados ainda melhores, aumentando-se ainda mais o nível de avivamento e detalhamento das cores. Indo de encontro as melhorias alcançadas nos métodos anteriores, a análise pelo contexto (vizinhança) da imagem gerou resultados inferiores, criando manchas azuladas em setores mais escuros. 


\section{REFERÊNCIAS BIBLIOGRÁFICAS}

[1] ESPECIFICAçõES do Produto. Disponivel no sítio www.hp.com/latam/catalogo/br/bwlje/sp/q5403a.html, 2008.

[2] SPECIFICATIONS. Disponivel no sítio h10010.www1.hp.com/wwpc/us/en/sm/WF06a/18972236251-236268-15077-f58-375773.html, 2008.

[3] GONZALEZ, R. C.; WOODS, R. E. Digital Image Processing. 2nd edition. ed. [S.1.]: Prentice Hall, 2002.

[4] CAMPUS, J. F. Mini-curso de Processamento de Imangens, Amostragem e Quantização. Disponivel no sítio http://www.ene.unb.br/ juliana/cursos/semana/lab1/ex3/, 2005.

[5] CONVERTENDO cor em nível de cinza. Disponivel no sítio http://http://pt.wikipedia.org/wiki/N\%C3\%ADvel-de-cinza.

[6] QUEIROZ, R. L. de. Improved reversible mapping from color to gray. In: . SIBGRAPI, Belo Horizonte, MG, Brazil: [s.n.], 2007.

[7] ROETling, P. G.; LOCE, R. P. Digital Image Processing Methods. 1 edition. ed. [S.1.]: CRC, 1994.

[8] QUEIROZ, R. de; BRAUN, K. Color to Gray and Back: Color Embedding Into Textured Gray Images. IEEE TRANSACTIONS ON IMAGE PROCESSING, INSTITUTE OF ELECTRICAL AND ELECTRONICS ENGINEERS, v. 15, n. 6, p. 1464, 2006. 
ANEXOS 


\section{EQUIPAMENTOS}

A analie quando feita para apenas um caso não tem grande valor devido a pequena fração que representa. A utilização de varios equipamentos, na medida da disponibilidade, permite uma contemplação maior do fenômeno analisado.

\section{I.1 Introdução}

Os equipamentos utlizados no decorrer do trabalho estão situados no GPDS. Modernos em sua maioria, permitiram o estudo dos processos, estando estes, muito próximos do que ocorre no cotidiano de empresas e reapartições atuais.

Para facilitar o entendimento por parte do leitor, foi feita a referência a cada equipamento como:

- Impressora 1: Impressora HP LaserJet 4250dtn

- Impressora 2: Impressora HP LaserJet 4650

- Scanner 1: Scanner HP ScanJet 3570c

\section{I.1.1 Impressora HP LaserJet 4250dtn [1]}

Impressora monocromática da sala de Hardware.

Figura I.1: Impressora HP LaserJet 4250dtn 
Tabela I.1: Descrição da Impressora HP LaserJet 4250dtn

\begin{tabular}{|c|c|}
\hline Diferencial do produto & \\
\hline Diferencial do produto & $\begin{array}{l}\text { Modelo básico mais Bandeja de entrada } 3 \text { de } 500 \text { folhas, } \\
\text { acessório de impressão em frente e verso, RAM de } 32 \mathrm{MB} \\
\text { adicional (memória RAM de } 80 \mathrm{MB} \text { no total), Servidor de } \\
\text { Impressão e HP Jetdirect Fast Ethernet Integrados }\end{array}$ \\
\hline Resolução & \\
\hline $\begin{array}{l}\text { Qualidade de resolução de } \\
\text { impressãootimizada, preto }\end{array}$ & Até 1200 x 1200 dpi \\
\hline Tecnologia & \\
\hline $\begin{array}{l}\text { Tecnologia de resolução } \\
\text { deimpressão }\end{array}$ & REt, HP ProRes 1200, HP FastRes 1200 \\
\hline Cartuchos & \\
\hline $\begin{array}{l}\text { Número de cartuchos } \\
\text { de impressão } \\
\text { Cores dos cartuchos } \\
\text { de impressão }\end{array}$ & $\begin{array}{l}1 \text { (preto) } \\
\text { Preto }\end{array}$ \\
\hline Conectividade & \\
\hline $\begin{array}{l}\text { Portas E/S externas } \\
\text { Pronto para rede }\end{array}$ & $\begin{array}{l}\text { Porta USB } 2.0 \text { de alta velocidade, porta paralela compatível } \\
\text { com IEEE 1284-B, } 2 \text { slots abertos EIO, Servidor de Impressão } \\
\text { Integrado HP Jetdirect Fast Ethernet } \\
\text { Servidores de impressão internos EIO HP Jetdirect, servidores } \\
\text { de impressão externos HP Jetdirect, servidores de impressão } \\
\text { sem fio HP, cartão de conectividade EIO HP Jetdirect } \\
\text { (para USB, serial, LocalTalk), Bluetooth sem fio } \\
1 \text { USB, } 1 \text { paralela, } 2 \text { EIO } \\
\text { Padrão }\end{array}$ \\
\hline Geral & \\
\hline $\begin{array}{l}\text { Linguagens da impressora, } \\
\text { padrão }\end{array}$ & $\begin{array}{l}\text { HP PCL 6, HP PCL 5e, emulação de HP Postscript Nível 3, } \\
\text { impressão (v 1.3) direta para PDF (com memória mínima de } \\
\text { impressora de } 128 \mathrm{MB} \text { ) }\end{array}$ \\
\hline Tipo de processador & MIPS 20Kc integrado \\
\hline $\begin{array}{l}\text { Descrição de administração } \\
\text { desegurança }\end{array}$ & $\begin{array}{l}\text { Segurança no gerenciamento: SNMP v } 3, \text { SSL/TLS (HTTPS), } \\
\text { autenticação 802.1x (com servidores de impressão EIO 620n e } \\
625 n \text { ); segurança de rede sem fio: WPA (Wi-Fi Protected Access), } \\
\text { criptografia WEP ( } 40 / 64 \text { e } 128 \text { bits), autenticação } 802.1 x \\
\text { (EAP-PEAP, LEAP, EAP-TTLS, EAP-TLS, EAP-MD5) com } \\
\text { servidores RADIUS }\end{array}$ \\
\hline Fontes embutidas & $\begin{array}{l}\text { Drivers de impressão e software de instalação em CD-ROM } \\
\text { (HP PCL 6, HP PCL 5e, PS, PPDs, HP LaserJet Utility, } \\
\text { HP LaserJet Toolbox, software para Macintosh) } \\
80 \text { conjuntos de fontes HP (além de Grego, Hebreu, Cirílico e Árabe) }\end{array}$ \\
\hline
\end{tabular}


Tabela I.2: Descrição da Impressora HP LaserJet 4650

\begin{tabular}{|l|l|}
\hline Speed/monthly volume & \\
\hline Print speed, black (best quality mode) & Up to $22 \mathrm{ppm}$ \\
Print speed, color (pages per minute) & Up to $22 \mathrm{ppm}$ \\
First page out, black & 15 seconds \\
First page out, color & 15 seconds \\
Processor speed & $533 \mathrm{MHz}$ \\
Recommended monthly volume, maximum & Up to 85,000 pages \\
\hline Print quality / technology & \\
\hline Print technology & Laser \\
Print quality, black & Up to 600 x 600 dpi \\
Print quality, color & Up to 600 x 600 dpi \\
Resolution technology & HP ImageREt 3600 \\
\hline Connectivity & \\
\hline Connectivity, std. & Bidirectional IEEE-1284-C parallel port, \\
& USB 1.1 port, HP Jetdirect 620n Fast Ethernet \\
& internal print server, 2 open EIO slots \\
Connectivity, opt. & HP Jetdirect EIO print servers for Ethernet \\
& (10Base-T, 10 Base2), 802.11b wireless \\
& Ethernet Token Ring, LocalTalk, serial and USB, \\
& Bluetooth wireless \\
\hline
\end{tabular}

\section{I.1.2 Impressora HP LaserJet 4650 [2]}

Impressora colorida de uso restrito ao grupo IMAGE.

Figura I.2: Impressora HP LaserJet 4650 


\section{I.1.3 Scanner HP ScanJet 3570c}

Scanner de uso comum do GPDS, não foi possível encontrar dados sobre o equipamento devido a idade elevada do mesmo.

Figura I.3: Scanner HP ScanJet 3570c 